
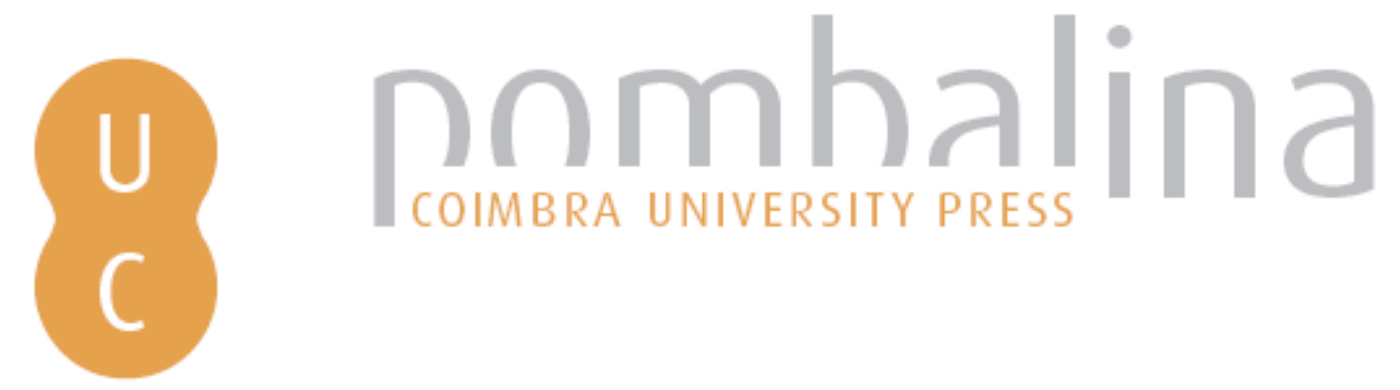

\title{
Gestão de caso e mediação social: abordagens, processos e competências cruzadas na agenda do conhecimento em serviço social
}
Autor(es):
Almeida, Helena Neves
Publicado por: Imprensa da Universidade de Coimbra
URL
persistente:
URI:http://hdl.handle.net/10316.2/30123
DOI:
DOI:http://dx.doi.org/10.14195/978-989-26-0769-6_1
Accessed : $\quad$ 26-Apr-2023 06:24:18

A navegação consulta e descarregamento dos títulos inseridos nas Bibliotecas Digitais UC Digitalis, UC Pombalina e UC Impactum, pressupõem a aceitação plena e sem reservas dos Termos e Condições de Uso destas Bibliotecas Digitais, disponíveis em https://digitalis.uc.pt/pt-pt/termos.

Conforme exposto nos referidos Termos e Condições de Uso, o descarregamento de títulos de acesso restrito requer uma licença válida de autorização devendo o utilizador aceder ao(s) documento(s) a partir de um endereço de IP da instituição detentora da supramencionada licença.

Ao utilizador é apenas permitido o descarregamento para uso pessoal, pelo que o emprego do(s) título(s) descarregado(s) para outro fim, designadamente comercial, carece de autorização do respetivo autor ou editor da obra.

Na medida em que todas as obras da UC Digitalis se encontram protegidas pelo Código do Direito de Autor e Direitos Conexos e demais legislação aplicável, toda a cópia, parcial ou total, deste documento, nos casos em que é legalmente admitida, deverá conter ou fazer-se acompanhar por este aviso.

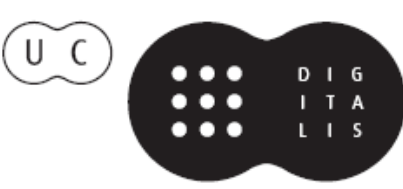




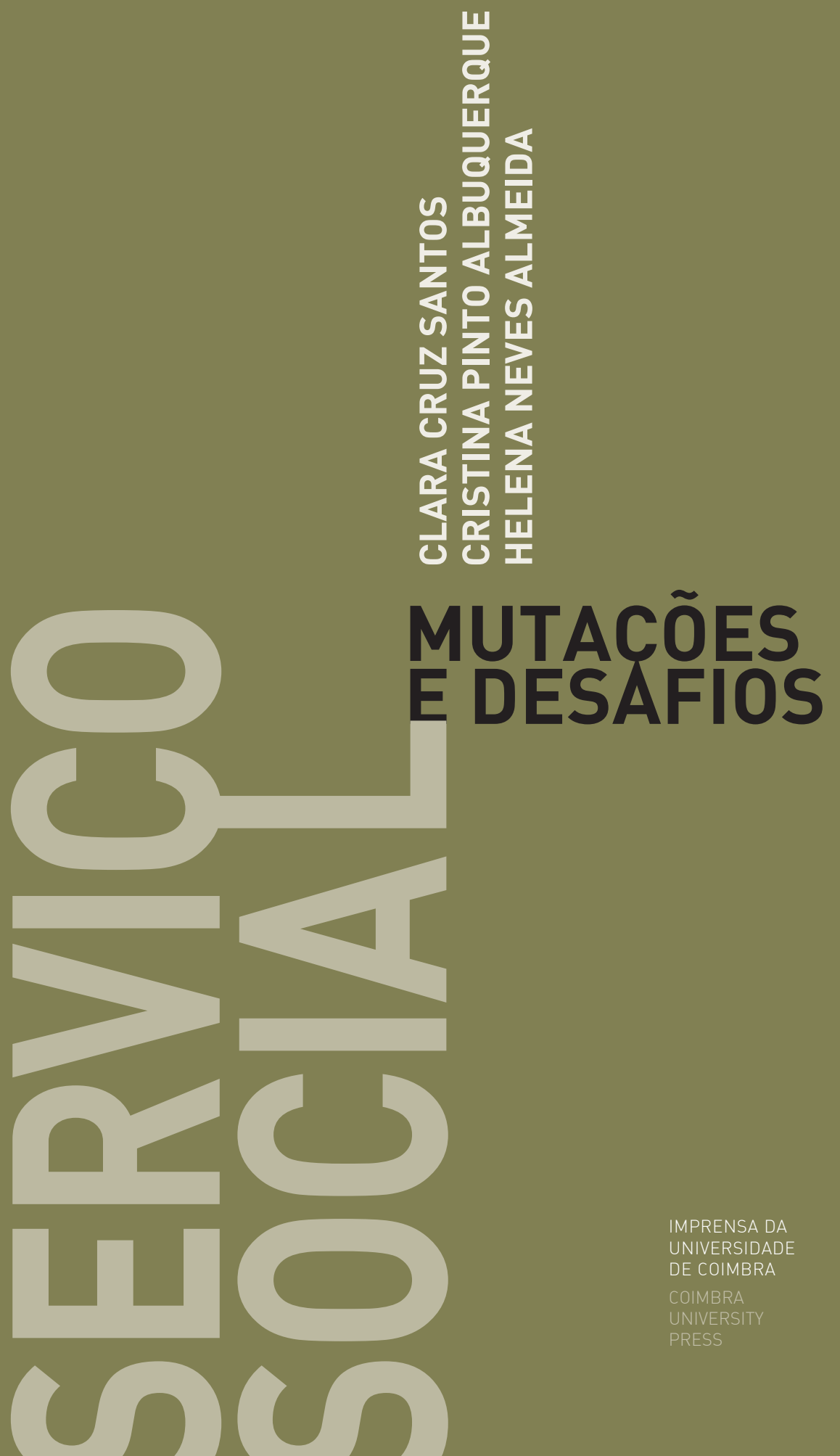


Helena Neves Almeida

\section{CAPÍTULO I}

\section{GeSTÃo de CASO E MEdiaÇÃo SOCIAL: ABORdagens, PROCESSOS E COMPETÉNCIAS CRUZADAS NA AGENDA DO CONHECIMENTO EM SERVIÇO SOCIAL}

\section{Introdução}

O debate sobre a construção do conhecimento e a relação entre teoria e prática no domínio do Serviço Social continua na ordem do dia por várias ordens de razão, de onde destacamos o seu caráter multi e interdisciplinar, o caráter complexo do seu modus operandi e ainda a relação entre oferta e procura, que no domínio social é dinâmica, movediça e pluridireccionada. Na convergência destes argumentos emergem abordagens, práticas e processos interventivos cuja especificidade se inscreve na agenda de construção e consolidação do seu conhecimento, designadamente a gestão de caso e a mediação social. Tratando-se de modos de intervenção residentes na matriz conceptual de serviço social, importa explorar a sua adequação e contornos performativos na sociedade contemporânea onde o risco, a incerteza e a desigualdade ocupam um lugar de relevo e exigem intervenções inovadoras e competências cruzadas.

Vivemos um período de grandes e inúmeras transformações sociais, económicas e políticas, inscritas e simultaneamente decorrentes da quebra do compromisso social entre o Estado e os Cidadãos, com uma reduzida margem de manobra para a construção de alternativas devido às dificuldades económicas existentes a nível individual, familiar e dos sistemas de proteção social. Daqui emergem ruturas sociais que potenciam conflitos e problemas sociais transformados em procuras sociais imprevistas, a que é difícil mas necessário, 
providenciar respostas e serviços no quadro dos direitos constituídos (desemprego qualificado e de longa duração, imigração, comportamentos de risco, envelhecimento e sobrecarga familiar, endividamento individual e familiar gerador de vulnerabilidades e de nova pobreza). Quebram-se os direitos, as normas mudam, e com elas reduz-se a capacidade de gerir de forma eficiente e eficaz os recursos necessários. A gestão de caso e a mediação social são hoje apontados como estratégias e métodos adequados do ponto de vista dos princípios que os orientam. Porém, e apesar das suas potencialidades e especificidades, apresentam limitações que se prendem com a volatibidade deste tempo e com o agudizar dos conflitos que as mudanças em curso produzem. A mudança, a liderança, a participação numa lógica colaborativa e cidadã, o trabalho em equipa, o trabalho em rede, bem como o estabelecimento de laços sociais correspondem a paradigmas de intervenção social na sociedade contemporânea, e constituem a matriz analítica dos modelos de intervenção que se vão configurando. O termo gestor de caso e mediador proliferam no campo social, em todas as áreas: na saúde, na educação, na reabilitação, na inserção social, na segurança social, na justiça, a nível familiar, com crianças, jovens, adultos e idosos, a nível organizacional e a nível comunitário. Por isso, consideramos pertinente analisar criticamente os fundamentos dos modelos em análise, no quadro das perspetivas do serviço social, identificar as suas características e produzir uma leitura reflexiva sobre os limites e as potencialidades deste modelo, cruzando olhares na procura de compromissos entre a estabilidade e a mudança social necessária.

\section{1 - Perspetivas analíticas sobre o Serviço Social: Posicionar o pensa- mento crítico sobre o projeto profissional na sociedade contemporânea}

A sociedade contemporânea, também designada sociedade do conhecimento é paradoxal. Nela convivem, e por vezes se confrontam, a potência ouro e a potência desespero, ladeadas por uma aparente igualdade de oportunidades no acesso à educação, ao direito, ao trabalho, plataformas de inovação científica e tecnológica; nela, a pobreza, a fome, o desemprego, a vulnerabilidade, o risco e a incerteza cruzam-se, e raramente se encontram, 
com os elevados índices de rendimento económico, o exercício do poder oriundo da posição social aliada ao capital financeiro, os luxuosos e elevados padrões de vida e de consumo daqueles que, sendo em número cada vez menor, mais possuem. Uma sociedade com estas características exige a construção e validação de múltiplas formas de ação e gestão ancoradas numa cidadania ativa. As situações de crise decorrentes de riscos naturais ou decorrentes da ação humana não têm fronteiras e constituem ameaças à coesão social e à cultura de paz que merecemos e desejamos. Conhecer e agir sob o paradigma da "sociedade de risco" exige novas competências pessoais e profissionais.

As profissões sociais têm sido assoladas por paradigmas teóricos construídos em contextos diferenciados a nível político, económico e social, mas também oriundos de diferentes disciplinas, tais como sociologia, psicologia, economia, antropologia, e mais recentemente gestão. Neste turbilhão de informações e de olhares analíticos e operativos cruzados, têm-se elaborado diversas representações, saberes e práticas profissionais, diferentemente ajustadas à melhoria da sociedade e à mudança e transformação social. No domínio do Trabalho Social (denominação anglosaxónica) são diversos os contributos teóricos subjacentes à análise tanto da intencionalidade da ação como dos processos, da eficiência e da eficácia da intervenção. Beulah Compton e Burt Gallaway (1999), Lena Dominelli (2004, 2009); Malcolm Payne (1999, 2008); Marc Lymbery e Karen Postle (2007), Kate Wilson, Gillian Ruch, Marklimbery e Andrew Cooper (2008), Saul Becker (2008), Alison Bramer (2008), Rachel Clauson (2008), Brian Littlechild (2008), Ian Paylor (2008), Roger Smith (2008), Mel Gray e Stephen Webb (2009), Barbra Teater (2010), Chris Beckett (2010), são algumas das referências atuais no plano da sistematização e da análise dos desafios que se colocam entre a teoria e a prática e das competências exigidas. Quando os contextos económicos, sociais, políticos e culturais da ação abrem alas à proliferação do risco, vulnerabilidade e incerteza, os atores profissionais se diversificam e especializam, os cidadãos se mobilizam para a conquista de maior equidade e justiça social, e as procuras sociais são diversas, múltiplas, complexas e interdependentes, é na relação entre oferta e procura que se desenham novos modelos de regulação social, novas ou renovadas abordagens e modelos de intervenção mais adaptados às novas realidades. 


\section{1 - A relação entre oferta e procura no domínio social}

A relação entre oferta e procura, sendo importante na definição e gestão de lacunas e de margens de liberdade e incerteza num processo de desenvolvimento social e mudança, não é uma dimensão passiva na análise do ajustamento necessário à satisfação das necessidades humanas, na medida em que à ausência de procura social não corresponde necessariamente a ausência de necessidade. Também a presença de uma oferta não significa que ela corresponda de forma adequada a uma necessidade, nem que a inadequação entre oferta e procura seja sancionada pelo mercado, dado o caráter excedentário da segunda em relação à primeira. Como referem Gaulejac, Bonetti et Fraisse, enquanto no setor do mercado

"a procura é apreendida a partir da agregação de procuras individuais, soma ou resultado de escolhas expressas pela compra de bens ou serviços divisíveis, apropriáveis, facilmente diferenciados, a procura social diz respeito a bens ou serviços coletivos não divisíveis e não apropriáveis. Ela é mais a expressão de uma política de Estado, das coletividades locais e das instituições do que a expressão de uma multiplicidade de processos individuais" (1989, p. 74).

Nas sociedades ocidentais, os sistemas de ação social revelam características de interdependência e complementaridade que estão presentes no decurso de ações de índole individual ou coletivo e que provocam efeitos no quotidiano da gestão e da intervenção social. As intervenções são direcionadas para situações particulares e, em relação a elas, as medidas podem adquirir diferentes configurações (Alfandari, 1987). Escapam à lógica da relação linear entre oferta - necessidade e procura as pessoas que têm necessidade mas não recebem qualquer apoio, pelo desconhecimento formal da sua existência, as que fogem às características do grupo-alvo a que os dispositivos se destinam e ainda aquelas que embora tenham uma necessidade reconhecida e expressa, não têm cabimento por insuficiência de recursos (Noguès, 1991, p. 174-176), isto é, situações marginais, não pela sua menor importância, mas pela sua menor visibilidade devido à ausência de mecanismos de registo e avaliação. 


\section{2 - Mandato institucional e projeto profissional}

No processo de intervenção social, é necessário ter bem claro qual o mandato institucional do trabalhador social e o seu projeto profissional. Como salienta Paulo Netto (2001) os homens agem sempre teleologicamente. As suas ações são sempre orientadas para objetivos-metas e fins, isto é, implicam sempre um projeto que é uma antecipação ideal da finalidade que se pretende alcançar, com a inovação dos valores que a legitimam e a escolha dos meios para a atingir. Apenas os projetos societários, aqueles que apresentam uma imagem da sociedade a ser construída, e que reclamam valores e privilegiam meios materiais e culturais para concretizar essa sociedade, possuem uma dimensão política que envolve relações de poder. O Serviço Social não constitui uma unidade identitária, ele está alicerçado na diversidade de origens e expectativas sociais, comportamentos e preferências teóricas, ideológicas e societárias distintas. Por isso, o Serviço Social é um espaço plural de onde poderão emergir projetos profissionais diferentes. "Toda a categoria profissional é um campo de tensões e lutas" (Netto, 2001, p. 15) e a afirmação de um projeto profissional não suprime divergências e contradições. Ela deve fazer-se através do debate, pela discussão, pelo confronto de ideias.

Como referem Cristina Maria Brites e Maria Lúcia Barroco

"A formação ética, pela sua natureza filosófica, é pressuposto essencial, tanto para o desvelamento crítico do significado das escolhas individuais em face dos projetos coletivos, quanto para orientar a construção de respostas profissionais que, diante dos desafios quotidianos, tenham a capacidade objetiva de romper, em algumas situações, ou de resistir aos limites da ordem burguesa" (idem 2001, p. 80).

O projeto profissional é um processo contínuo que se constrói no quotidiano, e que assenta numa proposta de resgate da centralidade da ética na formação profissional. A defesa e a reprodução dos princípios e valores éticos que lhe estão subjacentes exigem sujeitos profissionais ativos e autónomos. 


\section{2 - Referenciais analíticos do Serviço Social e projeto profissional}

Muitos dos dilemas éticos do Serviço Social resultam do confronto de perspetivas teóricas em contextos diversificados e distintos, em termos individuais e societais com as representações que se produzem no campo da ação. Identificam-se 3 debates essenciais (Figura 1): Perspetivas analíticas no âmbito da relação teoria prática; as abordagens conceptuais centradas na natureza do Serviço Social e os modelos conceptuais focalizados na intervenção. Os argumentos do debate posicionam-se, pois, em torno de três eixos analíticos: 1 - A perceção sobre os modos de apropriação, aplicação e produção de conhecimento, sob o prisma da relação dialética entre teoria, prática e valores; 2 - A natureza do Serviço Social, posicionando o debate nas suas raízes históricas associadas à ação curativa, preventiva, promocional e restauradora, de controlo e estabilidade social, mas também no caráter transformador associado ao projeto profissional de construção de uma sociedade mais justa e igualitária; 3 - Os modelos conceptuais e operativos focalizados na intervenção, designadamente no processo de interação, nas pessoas, na mudança e nas forças.

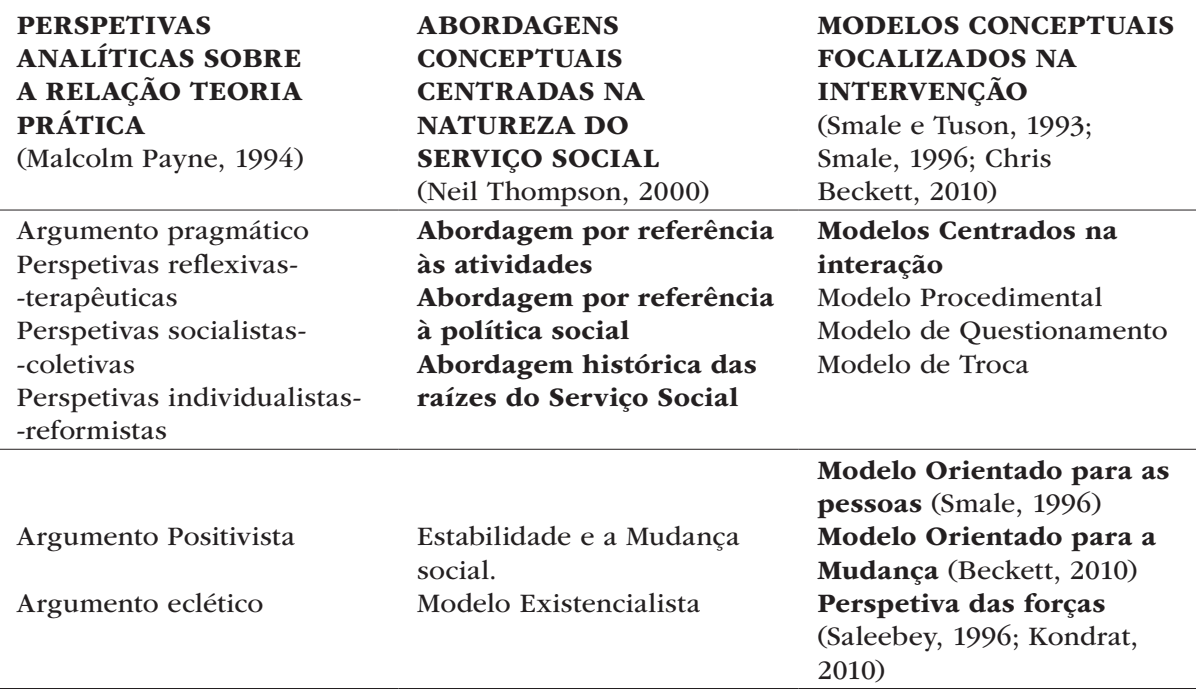

Figura 1 - Referenciais Analíticos do Projeto Profissional de Serviço Social Fonte: Elaboração da autora (2012) 
A matriz analítica aqui exposta coloca em evidência a diversidade de abordagens teóricas que fundam o projeto profissional, tomando por referência o contributo de autores como Smale e Tuson (1993), Payne (1994), Smale (1996), Saleebey (1996), Thompson (2000), Beckett (2010) e Kondrat (2010).

\subsection{1 - Perspetivas sobre a relação entre teoria e prática: diálogos plurais em vasos comunicantes}

Malcolm Payne (1994) identifica três argumentos, no que respeita à análise da relação entre teoria e prática, isto é, no que concerne à adequação da teoria à realidade interventiva e da relação do modus operandi com a teoria:

O argumento pragmático - que considera que existe um conjunto confuso de teorias, a maior parte importadas de diferentes contextos sociais, económicos e políticos. As dificuldades de aplicação à prática derivam de razões diversas, entre as quais salienta, por um lado, o caráter generalista de algumas teorias, pouco adequado à sua utilização em ações práticas específicas, e por outro lado, a existência de uma grande competição entre teorias, dificultando a escolha de uma delas;

O argumento positivista - que defende que muitas das teorias são insuficientemente rigorosas e não constituem verdadeiras teorias uma vez que descrevem e levantam hipóteses, mas não possuem um poder explicativo suportado por referencias empíricas. Segundo esta perspetiva, a compreensão da atividade humana deverá ser baseada na lógica dos métodos das ciências naturais e, por conseguinte, predizer comportamentos, partindo de métodos experimentais e de testes estatísticos;

O argumento eclético - que defende a ideia de que é possível usar diversas teorias ao mesmo tempo, de forma combinada. Segundo este argumento, os utentes devem poder beneficiar de todo o conhecimento disponível, uma vez que as teorias trabalham a diferentes níveis: por exemplo, a teoria centrada em tarefas proporciona uma orientação específica para situações particulares, enquanto as teorias psicodinâmicas permitem uma interpretação profunda do comportamento humano. Por outro lado, as teorias não cobrem todas as áreas de trabalho: por exemplo, a teoria marxista não fornece qualquer contributo a 
nível psicológico ou a nível técnico. Por isso, será possível fazer uso de diferentes teorias de forma combinada, no campo da prática profissional.

Ora, é no argumento pragmático, que o autor salienta a existência de três tradições separadas, três orientações analíticas, que contribuem para a formatação da representação conceptual do Serviço Social:

a) a tradição pragmática associada ao Serviço Social em serviços oficiais (Poor Law, Segurança Social) cuja componente de apoio económico é fundamental;

b) a tradição socialista que concentra reformas sociais, criticismo social e intervenção coletiva (grupos e comunidades);

c) a tradição terapêutica relacionada com indivíduos e grupos que apresentam problemas pessoais e dificuldades sociais.

Desta análise decorrem diferentes perspetivas de Serviço Social que na prática se cruzam, dificultando qualquer pretensa formulação unitária do projeto profissional:

\section{- Perspetivas reflexivas-terapêuticas}

O Serviço Social apresenta-se como um processo que procura melhorar o bem-estar da sociedade, dos indivíduos, dos grupos e das comunidades, através da promoção e da facilitação do crescimento e da realização pessoal. É um processo de influência mútua, em que há interação com outros profissionais, onde as ideias se vão modificando, tornando assim o serviço social reflexivo. Desta forma, tenta-se capacitar as pessoas para que superem os seus problemas.

\section{- Perspetivas socialistas-coletivas}

O Serviço Social é encarado como uma procura de cooperação e apoio mútuo na sociedade, para que as pessoas mais oprimidas e desfavorecidas 
possam ter poder sobre as suas próprias vidas. Assim, o objetivo do Serviço Social consiste em proporcionar às pessoas a possibilidade de se integrarem numa dinâmica de participação e cooperação no processo de criação de uma instituição ou iniciativa, onde todos possam participar. Através de uma posição critica às práticas que criam opressão e desfavorecimento, o Serviço Social tenta incrementar relações mais igualitárias na sociedade. Embora procure a realização pessoal, como referido nas perspetivas reflexivas-terapêuticas, os interesses das elites deitam por terra muitas das aspirações dos mais desfavorecidos.

\section{- Perspetivas individualistas-reformistas}

O Serviço Social é analisado na ótica da prestação de serviços de assistência aos indivíduos na sociedade. Pretende ir ao encontro das necessidades dos indivíduos, tornar as sociedades mais igualitárias e promover a realização pessoal e social através do crescimento individual. No entanto, estas ideias não são totalmente realistas, na medida em que uma mudança individual de pequena escala não produz mudança social. Para além disso, aqueles que financiam e aprovam as atividades do trabalhador social não pretendem grandes mudanças sociais, mas sim uma melhor adequação entre a sociedade e o indivíduo.

\subsection{2 - Abordagens concetuais centradas na natureza do Serviço Social}

Também Neil Thompson (2000) especifica três parâmetros na análise do Serviço Social: Abordagem por referência às atividades - Serviço Social é aquilo que os trabalhadores sociais fazem; Abordagem por referência à política social - o Serviço Social integra-se no conceito de bem-estar social; Abordagem histórica das raízes do Serviço Social - o Serviço Social balança entre o equilíbrio e o consenso da estabilidade social e a tensão da mudança.

É sobretudo no âmbito desta última abordagem que o autor desenvolve o seu pensamento. Considera que, o Serviço Social como agente de estabili- 
dade social, assegura que o nível de descontentamento não atinja níveis de desordem social. O projeto profissional centraliza-se no processo de normalização e controlo social. O modelo clínico, cujas etapas metodológicas são o estudo, diagnóstico e tratamento, é uma referência nesta abordagem. O trabalhador social assume-se como um perito que ocupa uma posição de poder, do ponto de vista do diagnóstico; embora as circunstâncias sejam relevantes, focaliza-se no problema como "patologia" muito ligado ao indivíduo e à família, e o sucesso da intervenção reside na "cura" ou "alívio do sintoma" de forma a facilitar o retorno do sujeito à sociedade "saudável". Ora, esta perspetiva concetual do Serviço Social negligencia as tensões e as divisões que ocorrem na sociedade; O processo de interpretação e especificação de um projeto profissional alternativo conduziu à emergência uma nova visão, a abordagem radical de Serviço Social, que o encara como parte da mudança e melhoria da sociedade e adota uma posição crítica em relação ao caráter de controlo social que lhe está associada. A perspetiva de consenso é substituída por uma visão da sociedade onde coexistem conflitos e tensões sociais ligadas a diferenças de classe, raça e género. $\mathrm{Na}$ perspetiva de Serviço Social orientado para a mudança, compete ao profissional apoiar a luta das populações contra a desigualdade e a discriminação social, abanando a posição de neutralidade profissional e superando a conceção redutora de intervenção baseada na dimensão técnica da resolução de problemas no sentido do compromisso com a promoção da igualdade, equidade e justiça social.

A análise reflexiva que o autor tece sobre a possibilidade de combinação das duas perspetivas, conclui que o modelo clínico reduz a complexidade dos problemas a disfunções individuais e/ou familiares, enquanto a abordagem radical se centraliza no contexto sociopolítico e hipervaloriza a importância do poder e da desigualdade no desenvolvimento dos problemas sociais. Por isso, o autor defende que é necessário combinar o otimismo em relação à mudança e o realismo em relação aos obstáculos e limites para o sucesso, salientando que as duas abordagens não se anulam (Figura. 2).

Trabalhar para a mudança não significa desvalorizar a estabilidade social. As duas abordagens complementam-se. O trabalhador social pode legitimamente apelar à estabilidade sem reforçar as desigualdades e injustiças sociais. 


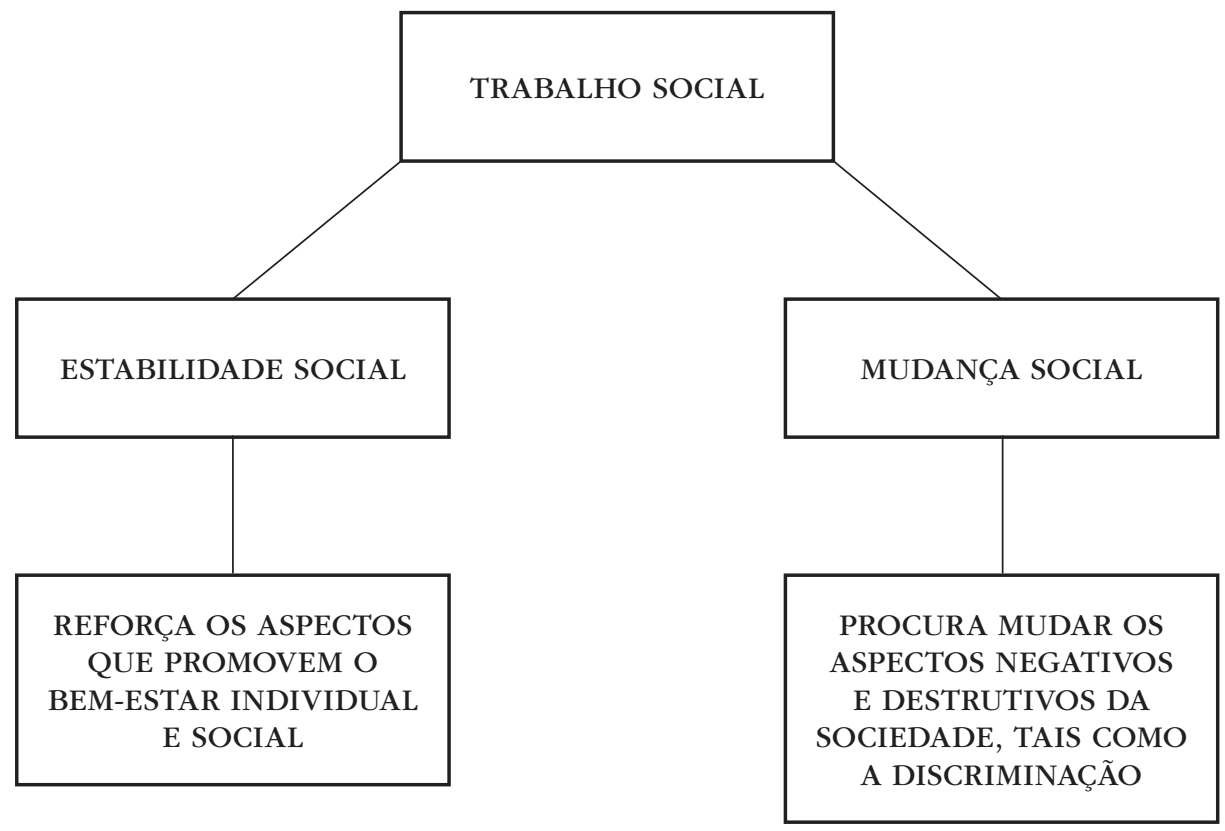

Figura 2 - Conceção de Serviço Social (Social Work)

Fonte: Neil Thompson (2000, p. 19)

O autor propõe, então, um modelo conceptual de Serviço Social existencialista, com os seguintes princípios:

1 - Ontológico: sensível às dimensões pessoais e sociais e sua interação.

2 - Focalizado no problema: sensível e compreensivo quanto aos desafios existenciais

3 - Sistemático: focalizado no que se faz e porque se faz (objetivos, metas, ...)

4 - Reflexivo: aberto ao novo, à capacidade em aprender, mais do que uma abordagem rígida e rotineira da prática.

5 - Emancipatório: harmonizado para o apoio à luta contra a desigualdade, a discriminação e a opressão sociais.

A questão coloca-se em perceber os limites desta aceção, quando a estabilidade é assente em premissas que colocam em causa não apenas o bem-estar 
individual, mas sobretudo os direitos humanos e sociais e o princípio da justiça social e da cidadania. O princípio da reflexividade e da emancipação propostos tendem a perspetivar uma conceção comprometida com a análise

e a reflexão ao serviço da mudança e da justiça social. Aspetos como participação, empowerment e cidadania não aparecem referenciados neste modelo analítico, ficando de fora a dimensão política e macro do Serviço Social, que não desvaloriza as forças e a criação de estruturas de oportunidade.

\subsection{3 - Modelos conceptuais focalizados na intervenção}

A análise do Serviço Social focalizada no processo de intervenção, na forma de agir, nos procedimentos utilizados conduz-nos a perceber uma outra dimensão analítica. Smale e Tuson (1993, in Beckett, 2010, p. 36) especificam três modelos de interação entre profissional e "cliente":

1 - O Modelo Procedimental, assente no uso de formulários institucionais, menos performativo de mudanças, mais rígido do ponto de vista da interação. O diagnóstico emerge condicionado ao perfil equacionado para o trabalhador social. O seu mandato institucional e funcional é redutor e alienante: Recolher informação pre-estruturada e em função dessa informação, agir em conformidade com os procedimentos correntes e identificados na organização;

2 - O Modelo Questionamento, que faz depender a intervenção da capacidade do trabalhador social procurar indícios, configurar questões adequadas à compreensão do problema, e que hipervaloriza as competências individuais do trabalhador social;

3 - O Modelo de Troca, que preconiza que o processo de recolha de informação, avaliação, planeamento e ação constituam um contínuum de partilha entre trabalhador social e "cliente", um processo participado e cooperativo.

Privilegiar qualquer dos modelos referidos por estes autores, transforma uma prática rica do ponto de vista dos contextos, das situações, dos 
stakeholders, dos processos e das orientações profissionais, numa prática vazia de sentido. A riqueza do Serviço Social está na diversidade social, teórica e prática e nos fins a que se propõe.

Smale (1996, in Coulshed, Mullender, Jones e Thompson, 2006, p. 84),

define a sua proposta de modelo orientado para as pessoas como um modelo próprio do Serviço Social na gestão da mudança. A proposta deste autor consiste em definir claramente as componentes do processo mesmo antes do início da ação, de forma a assegurar a participação das pessoas envolvidas na mesma. Para o efeito, é necessário considerar os seguintes aspetos: Planificar com as pessoas envolvidas na ação; Partilhar o problema com essas pessoas, para que elas tomem parte na construção da solução e no seu desenvolvimento, trabalhando para a sua eficácia; Identificar pessoas significativas e ligações para mudanças particulares que poderão ser necessárias; Encarar a gestão do processo de mudança como um dos trabalhos com as pessoas envolvidas; Reconhecer que todas as novas formas de trabalho, as novas tecnologias e as novas políticas têm implicações de mudança para o staff. A mudança individual ou coletiva pressupõe, pois, o desenvolvimento de processos participativos, pelo que pensar o Serviço Social sem esse pressuposto e sem a sua integração nas metodologias e processos de trabalho constitui um limite redutor do saber profissional. Porém, encontramos este desiderato em diversas abordagens e modelos de intervenção, tais como, a intervenção centrada na relação (Wilson, Ruch, Lymbery e Cooper, 2008), a prática reflexiva (Schon, 1987), a perspetiva das forças (Saleebey, 1996; Kondrat, 2010), a engenharia social (Gaulejac, Bonneti et Fraisse, 1989), o empowerment (Thompson, 2007; Adams, 2008), a intervenção em rede (Sanicola, 1994; Duhme, 2001, Guadalupe, 2009) e a mediação social (Freynet, 1996; Boudon, 1998; Almeida, 2001).

$\mathrm{Na}$ medida em que a mudança constitui um processo lento e contínuo, exige um posicionamento de abertura em relação aos atores, aos contextos e às práticas, capaz de introduzir uma dinâmica no pensamento e na ação que coloque em causa o adquirido, o invariável e o inerte. Chris Beckett (2010), apoiando-se no contributo estruturado de Prochaska, DiClement e Norcross (1992, p. 1102-14, in Beckett, ibidem, p. 138), sintetiza um conjunto de intervenções representativas de processos de mudança, (Figura 3). 
INTERVENÇÕES EM PROCESSOS DE MUDANÇA

Consciencialização (aumento de informação sobre si próprio e sobre o problema);

Autorreavaliação (avaliação das formas de sentir e dos seus pensamentos em relação à situação),

Autolibertação (escolha e compromisso com a ação e crenças nas possibilidades de mudança);

Intervenções anticondicionamento (alternativas para problemas de comportamento);

Controlo de estimulação (evitar ou confrontar estímulos que interferem no comportamento);

Gestão de reforços (compensações); relações de ajuda (estar aberto e confiante em quem presta cuidados);

Alívio da dramatização (experiência e expressão de sentimentos);

Reavaliação do contexto (avaliação sobre a forma como os problemas afetam o meio físico);

Libertação social (aumento de alternativas na sociedade para comportamentos não problemáticos, aumento de poder, intervenções políticas).

Figura 3

Fonte: Adaptação de Beckett, 2010, p. 138

Esta sistematização espelha a multiplicidade de mudanças possíveis, face à complexidade e diversidade de contextos de intervenção (a nível micro, meso e macro) e coloca como possível a complementaridade de ações profissionais, num jogo de opções entre a procura de estabilidade e controlo social e a promoção de mudanças a nível pessoal e social.

$\mathrm{Na}$ área da saúde mental, a perspetiva das forças tem-se apresentado como adequada, apesar da necessidade de aumentar a investigação neste domínio, sendo definida por Glicken (2004) como

"(a) way of viewing the positive behaviors of all clients by belping them see that problem areas are secondary to areas of strenghts and that out of what they do well can come helping solutions based upon the successful strategies they use daily in their lives to cup with a variety of important life issues, problems and concerns" (in Kondrat, 2010, p. 38). 
As forças podem ser apreendidas teoricamente com base na proposta triangular de Saleebey (2009) - CPR -, em que C reporta a competências, capacidades e coragem, $\mathrm{P}$ a promessas (aspirações), possibilidades e probabilidades (expectativas exequíveis) e $\mathrm{R}$ para resiliência, reservas e recursos de várias naturezas. De acordo com Greene e Lee (2002, in Kondrat, 2010, p. 39), as forças podem constituir um atributo pessoal ou contextual, com potencial para fomentar o crescimento e aparecimento de soluções, podendo residir no sujeito ou na comunidade em que este se integra. São essas três forças que ativam a capacidade das pessoas para lidar com a dificuldade e com o stress, para se libertar de trauma significativo, para usar desafios externos como estímulos ao crescimento, e para usar redes sociais de suporte como fontes de resiliência.

Os eixos distintivos desta perspetiva passam, desde logo, por deslocar o enfoque do Serviço Social do seu âmago tradicional (os problemas) para um outro, que substitui a centralidade atribuída ao deficit pela centralidade das forças. Deste modo, esta perspetiva distingue-se pelo relevo e a ênfase nas forças como oportunidades, na sua identificação e sua consolidação no processo do Serviço Social, tomando-as como recursos acionáveis ao longo de todo o acompanhamento dos sujeitos.

\section{2 - Gestão de Caso e Mediação em Serviço Social: especificidades concetuais e orientações metodológicas}

A procura em Serviço Social é nodular e consequente. O seu caráter nodular advém da complexidade e multidimensinalidade dos problemas e motivações que estão subjacentes ao movimento de procura, e é consequente porque traduz a previsibilidade de mudança, a partir do início do processo desde o estudo, à construção e ao desenvolvimento das alternativas sociais. Não se fazem relatórios, não se produzem pareceres para ficarem fechados numa gaveta. Eles são um instrumento necessário que objetiva e legitima a mudança possível. Não se promovem atividades para que elas se esgotem na sua visibilidade, elas constituem mediações entre meios-fins adequadas às necessidades de mudança diagnosticadas e consentidas pelo utente. 
O utente espera do Assistente Social o seu envolvimento na procura de uma solução, de cariz pessoal / familiar, institucional ou política, que diminua os efeitos do problema tanto a nível pessoal como a nível do seu enquadramento sociofamiliar ou profissional ou que possa imprimir uma dinâmica transformadora, em situação de mudança, de resistência à mudança ou para a mudança. Uma ação de caráter pessoal quando a resolução da situação passa por uma análise e possível aconselhamento a nível de atitudes e comportamentos a adotar na relação consigo próprio, com os outros e com o mundo que o rodeia, ou a nível do acesso aos serviços e cuidados prestados; uma ação a nível institucional, quando a solução passa pela utilização dos recursos disponibilizados pelo serviço a que recorre ou outros, e uma ação de cariz político quando, consciente das limitações de solução, o utente acredita e reconhece autoridade e competência ao Assistente Social para interferir na criação de respostas alternativas.

O Serviço Social cujo desenvolvimento foi construído sobre o "adoçar a miséria" reivindica um lugar cada vez mais importante na gestão dos problemas sociais (Tachon, 1985) e na regulação social sobre o estatuto dos indivíduos e grupos sociais, sobre um conjunto de direitos e deveres económicos, jurídicos, dos costumes e morais que confere ao indivíduo o seu lugar na sociedade (Dutrenit, 1983).

A instituição reconhece competência ao Assistente Social para interferir na procura e atribuição dos recursos e serviços disponíveis, ou na criação de respostas alternativas, e o utente deposita nele a sua esperança. Nesta relação, o Assistente Social assume um papel de elo de ligação na procura de solução e essa intervenção poderá revestir diferentes perfis, no quadro dos modelos de intervenção adotados.

\section{1 - A Gestão de Casos: da Estratégia ao Modelo Identitário de Serviço Social}

Veronica Coulshed, Audrey Mullender, David Jones e Neil Thompson consideram que existe uma relação intrinseca entre Serviço Social e gestão, a ponto de afirmar que "Every social worker has a part to play in management, 
and every manager, social work qualified or not, has a lot to learn from social work" (2006, p. 224). No entanto, a articulação entre Serviço Social e Administração e Gestão nem sempre é bem explícita, e pode assumir diversas conotações, umas de caráter executivo (racionalização da assistência, administração de recursos, supervisão de equipas, gestão de equipamentos) e outras de perfil mais performativo (gestão de problemas, gestão social, gestão de projetos, engenharia social, gestão de expectativas, gestão de redes).

O termo "gerencialismo" (managerialism) corresponde à tendência genericamente utilizada para descrever mudanças ocorridas recentemente nos serviços sociais em várias partes do mundo. A emergência da perspetiva de gestão social economicista radica na análise de que é possível otimizar a utilização dos recursos com menores custos e a sua operacionalização assenta nas seguintes princípios: a gestão é uma função organizacional separada e distinta; O progresso é analisado em termos de aumento de produtividade; O aumento de produtividade resulta da aplicação de informação e tecnologias organizacionais; privilegia-se a abordagem quantitativa na perspetiva dos inputs, outputs e receitas; aposta-se na quantificação e na mensuração; os mecanismos de mercado devem ser usados para produzir serviços; devem ser introduzidas relações contratuais (Adapted from Pollitt, 1990, p. 2-3, 2003, p. 27-28, in White and Harris, 2007, p. 243).

As relações de poder entre profissionais e gestores alteram-se à medida que se atribui aos gestores a responsabilidade de alcançar economia, efici-

ência e eficácia e exercer maior controlo sobre aqueles. Aparentemente o termo "gerencialismo" é apresentado com a missão de transformar, atribuindo-se-lhe um sentido técnico, objetivo e neutro, a melhor via para remover dificuldades políticas. Na realidade tem contribuído para a descaracterização do papel do trabalhador social e da identidade do Serviço Social.

\subsection{1 - Regulação da Gestão de Caso: Conceitos e Orientações práticas}

A estratégia de Gestão de Caso (GC) foi adotada no campo da saúde após a II Guerra Mundial, através das companhias de seguros, para assegurar a coordenação dos serviços prestados aos combatentes com complexas lesões 
que exigiam intervenções multidisciplinares. Por isso, a gestão de cuidados está intrinsecamente associada ao conceito de gestão de casos. Nos anos 70, em contexto de dificuldades económicas e mudanças sociais e políticas, o Modelo Gestão de Caso adicionou à coordenação de serviços prestados, a necessidade de controlo de custos, passando a ser considerado como uma estratégia útil para a eficiência e eficácia das medidas sociais e dos serviços prestados.

O Conceito de Gestão de Casos foi pela primeira vez definido em 1993, pela National Case Management Task Force, da Sociedade Americana de GC, tendo sido definidas em 1995 e revistas em 2002 as Regras da Prática para a Gestão de Casos (Standards of the Practice for Case Management), de forma a garantir no futuro padrões de qualidade nos serviços prestados pelos seus profissionais.

A conceção de Gestão de Caso como processo colaborativo "com vista a responder com qualidade às necessidades e potencialidades dos indivíduos [que] implica o investimento na comunicação e utilização eficiente e eficaz dos recursos disponiveis" (CRPG, 2007, p. 3), vem na linha da que foi defendida pela American Hospital Association (1987) mas é mais redutora do que a proposta por Moxley (1989), segundo o qual a gestão de casos se traduz num sistema de prestação de serviços que organiza, coordena e sustenta uma rede de apoios formais e informais e atividades que otimizam o bem estar das pessoas com múltiplas necessidades. Ainda segundo o mesmo autor, as atividades desenvolvidas visam promover, quando possível, as competências dos clientes para o acesso e utilização dos recursos, desenvolver a capacidade das redes sociais e dos serviços que promovem o bem estar do cliente, promover serviços eficazes. Por isso, pode ser considerada uma estratégia de ação e coordenação integrada que mobiliza e articula serviços, coloca em ação diversas competências, pressupõe um trabalho cooperativo de múltiplos profissionais, um trabalho em equipa com a partilha de responsabilidades e papéis, promove a participação ativa das pessoas, numa lógica de empowerment e de respeito pela pessoa e pela diferença, altera a forma de pensar e intervir, confrontando modelos de intervenção centrados no problema e promovendo uma nova atitude profissional.

O conceito atualmente aceite de GC é o definido em 2010: 
Case management is a collaborative process of assessment, planning, facilitation, care coordination, evaluation, and advocacy for options and services to meet an individual's and family's comprehensive health needs through communication and available resources to promote quality cost-effective outcomes" (CMSA, 2010, p. 8),

plasmado no Relatório produzido sobre os Normas da Prática de GC. A GC constitui um processo colaborativo, isto é, que implica participação em todas as fases de intervenção, desde a avaliação diagnóstica, planeamento, facilitação, coordenação de cuidados, avaliação e advocacy para a tomada de decisão e serviços que respondam às necessidades de saúde dos Indivíduos e das famílias, através da comunicação e recursos disponíveis, de forma a promover resultados de qualidade a nível de custo-benefício.

$\mathrm{O}$ processo GC parte da premissa de que quando o indivíduo atinge o nível ótimo de bem-estar e de capacidade funcional, todos beneficiam: Os indivíduos que estão a ser apoiados, os seus sistemas de apoio, os sistemas de prestação de cuidados de saúde e as várias fontes envolvidas. A Gestão de Caso é um meio para atingir o bem-estar e autonomia através do advocacy, comunicação, educação, identificação de recursos e facilitação de serviços. A prestação de serviços resulta melhor num clima que permita a comunicação direta entre o gestor de caso, o "cliente" e os serviços pessoais adequados, de forma a otimizar os resultados para todos os envolvidos. Como referem Franklin, Solovitz, Mason, Clemons \& Miller (1987, p. 677) " $\mathrm{um}$ dos elementos-chave da gestão de casos é providenciar aos clientes aquilo que eles precisam, quando precisam e o pretendem, durante o tempo que for necessário".

Early \& Poertner (1993, in Compton and Galaway, 1999, p. 367) identificam 5 princípios orientadores da gestão de casos, que estão na génese da sua identidade: Avaliação de necessidades e problemas; Planeamento, assumindo os objetivos visados e as atividades e serviços necessários para que os mesmos sejam atingidos; Articulação que permite a referenciação, o encaminhamento ou o estabelecimento de ligações com outros serviços que os clientes necessitem; Monitorização, assegurando que os serviços requeridos estão a ser prestados se mantêm adequados e tem em conta a avaliação 
dos progressos registados; Advocacy, isto é, intervenção em nome do cliente para assegurar serviços e direitos.

De acordo com os Standards of Practice for Case Management (CMSA, 1993, 1995, 2010), a GC desenvolve-se com base em princípios e funções atribuídas ao gestor (Figura 4). A promoção e defesa dos direitos do cliente, a intervenção orientada para o cliente e para os resultados, a conceção da pessoa como um ser holístico e indivisível, de onde decorre a multidimensionalidade das intervenções, o trabalho em rede e de parcerias que se constituem como eixos centrais para a obtenção dos resultados esperados, a criação de oportunidades e condições que assegurem a participação dos clientes e pessoas significativas, e o facto de a mudança ocorrida na qualidade de vida do indivíduo ter um efeito multiplicador na rede que o suporta e na sociedade, configuram-se como os aspetos mais positivos do processo.

A dimensão estratégica e política que lhe está associada, conduz-nos a considerar, que a GC tem essencialmente duas funções: a de resolução de problema no sentido de garantir a continuidade dos serviços e ultrapassar os sistemas rígidos, os serviços fragmentados, a má utilização de certos equipamentos, bem como problemas de acessibilidade; a segunda função constitui o eco da primeira e desenvolve-se no sentido da advocacy, self-advocay e empowerment dos sujeitos, dos sistemas e político.

Case management is a "political" system. Case managements success depends in large part on the willingness of established institutions to change their traditional ways of doing business. [...] At the systems level, case management may be defined as a strategy for coordinating the provision of services to clients within that system. At the client level, case-management may be defined as a client-centered, goal-oriented process for assessing the need of an individual for particular services and obtaining those services.(Hahn, Aaron and Kingsley, 1989, p. 2)

Destarte, a GC, submetida ao padrão de controlo de custos, tem mostrado um efeito em sentido contrário, na medida em que procura maior eficiência e eficácia dos recursos e serviços prestados. Efetivamente, ao aumentar a acessibilidade e a utilização dos recursos e serviços disponíveis e diversos, bem 
1. Uso de uma abordagem centrada no cliente e de parceria colaborativa;

2. Se possível, facilitar a autodeterminação e autonomia de cuidados através de princípios de advocacy, partilha da tomada de decisões e educação;

3. Usar uma abordagem compreensiva holística;

4. Mostrar competência cultural, com consciência e respeito pela diversidade;

5. Promover a utilização de cuidados baseados na evidência, de acordo com a disponibilidade existente;

6. Promover segurança de excelência ao cliente;

7. Promover a integração da ciência da mudança comportamental e princípios.

8. Fazer a articulação com recursos da comunidade;

9. Apoiar o acesso ao sistema de saúde para um bom acesso aos cuidados, por exemplo durante as transições.

10. Perseguir a excelência profissional e manter a competência prática;

11. Promover resultados de qualidade com medição dos resultados;

12. Apoiar e manter a conformidade com a legislação existente.
1. Avaliação das Necessidades: "Conducting a comprehensive assessment of the client's health and psychosocial needs, including health literacy status and deficits, and develops a case management plan collaboratively with the client and family or caregiver";

2. Planeamento colaborativo: "Planning with the client, family or caregiver, the primary care physician/ provider, other health care providers, the payer, and the community, to maximize health care responses, quality, and costeffective outcomes";

3. Facilitação da Comunicação: "Facilitating communication and coordination between members of the health care team, involving the client in the decision-making process in order to minimize fragmentation in the services";

4. Educação para a Tomada de Decisão:

"Educating the client, the family or caregiver, and members of the health care delivery team about treatment options, community resources, insurance benefits, psychosocial concerns, case management, etc., so that timely and informed decisions can be made";

\section{Aumento de Competências do Cliente:} "Empowering the client to problem-solve by exploring options of care, when available, and alternative plans, when necessary, to achieve desired outcomes";

\section{Encorajamento do uso adequado dos} serviços: "Encouraging the appropriate use of health care services and strives to improve quality of care and maintain cost effectiveness on a case-by-case basis";

7. Apoio ao Cliente em momentos de transição "Assisting the client in the safe transitioning of care to the next most appropriate level";

8. Promoção da Autorregulação do Cliente: "Striving to promote client self-advocacy and self-determination";

9. Advocacia Social: "Advocating for both the client and the payer to facilitate positive outcomes for the client, the health care team, and the payer. However, if a conflict arises, the needs of the client must be the priority". 
como a sua otimização em termos de aproveitamento de sinergias, produz maiores custos (Franklin, Solovitz, Mason, Clemons \& Miller, 1987; Morse et al. 1997). Um outro aspeto decorrente da abordagem económica da Gestão de Caso prende-se com o aumento de burocracia no desempenho dos gestores, de onde se salienta a sobrecarga que a exigência de mensuração traduz no quotidiano profissional, designadamente a referenciação dos clientes e dos serviços em diversas plataformas informáticas e os relatórios solicitados para efeitos estatísticos, que mina uma das características essenciais da GC: a perspetiva colaborativa e verdadeiramente participativa que exige um planeamento estratégico e um trabalho intensivo com os indivíduos, as famílias, as organizações e outros profissionais, no sentido do aumento da sua autonomia, responsabilidade e bem-estar.

\subsection{2 - Gestão de Caso em Serviço Social: conceito, contextos e perspetivas}

Como uma abordagem conceptual e operativa orientada para a organização e coordenação de cuidados, a GC tem suas origens no início da história do Serviço Social e da profissão de assistente social. O método de Gestão de Casos em Serviço Social está claramente ligado ao Casework (Serviço Social de Casos), focalizado na pessoa e no meio ambiente, integra a ação direta ou indireta em nome de clientes individuais e famílias que manifestam a necessidade de prestação de serviços sociais. A GC continua a ser um componente profissional da competência do Serviço Social, e baseia-se no reconhecimento da força que a relação de confiança entre o trabalhador social e o "cliente" tem para o acesso e benefício de serviços ao longo de um continuum de cuidados e para a restauração ou manutenção do funcionamento autónomo possível. Esta abordagem à prestação de serviços tem-se tornado cada vez mais proeminente em muitas disciplinas e cenários de prática, por se considerar um método eficiente e eficaz (custo-benefício) para a gestão da prestação de múltiplos serviços de trabalho intensivo, às populações-alvo. Integra um corpo de conhecimentos de Serviço Social, perícia técnica e valores humanistas que permitem a prestação de um serviço especializado e exclusivo para grupos de clientes específicos. 
Em Serviço Social, compete ao Gestor de Caso a prestação de assistência de forma sensível e solidária ao cliente e às populações com base no conhecimento do comportamento humano e habilidades de observação e de comunicação, em contextos diversos. O trabalhador social - gestor de caso - integra um serviço ou uma equipa no âmbito de organizações sociais que providenciam serviços designadamente, em escolas, hospitais e outras instituições de saúde, serviços de reabilitação, equipamentos de proteção social a idosos, menores, deficientes e doentes mentais, serviços de formação e inserção profissional e social: estabelece relações de ajuda, avalia problemas complexos, promove a resolução de problemas e ajuda os clientes a funcionar de forma eficaz (Figura 5).

Nos termos dos Standards for Social Work Case Management da NASW (1992; 2012), a Gestão de Caso é um método de Serviço Social, orientado por princípios e adequado à complexidade das necessidades e à exigente coordenação de serviços prestados aos indivíduos, famílias e populações. É precisamente esta a característica que diferencia a GC em Serviço Social da que se opera noutros domínios. A GC destina-se tanto ao cliente na perspetiva biopsicossocial como aos sistemas sociais em que intervém. "Distinct from other forms of case management, social work case management addresses both the individual client's biopsychosocial status as well as the state of the social system in which case management operates" (NASW; 1992, p. 3).

Princípios e estratégias da GCSS

1. Desenvolvimento de Competências: Aumentar as capacidades de desenvolvimento, resolução de problemas, e coping dos clientes

2. Humanização e eficácia dos sistemas: Criar e promover $o$ funcionamento eficaz e humano dos sistemas que fornecem recursos e serviços às populações

3. Trabalho de rede: Ligar as pessoas aos sistemas que lhes fornecem recursos, serviços e oportunidades

4. Aumentar a proficiência dos serviços: Melhorar o âmbito e a capacidade do sistema de prestação de serviços
Tarefas e Funções do Gestor de Casos em SS

INTERVENÇÃO A NÍVEL DO CLIENTE

1. Avaliação colaborativa das forças e limitações do cliente e dos recursos sociais, financeiros e institucionais disponíveis

2. Implementação do plano, com a Mobilização dos Recursos Formais e Informais adequados à maximização do bem-estar do cliente (necessidades físicas, sociais e emocionais) e a coordenação e avaliação dos Serviços prestados

3. Exercício de autoridade adequada ao favorecimento do acesso, execução, acompanhamento, avaliação dos serviços, de forma a reduzir a fragmentação dos sistemas, promovendo a eficiência 
5. Cooperação estratégica: Contribuir para o desenvolvimento e melhoria da política social
INTERVENÇÃO A NÍVEL DO SISTEMA

4. Envolvimento em Atividades de Apoio que melhorem os sistemas onde se integra: Análise das forças e limitações, delineamento dos resultados, seleção e avaliação de estratégias potenciadoras dos sistemas, revisão do processo.

5. Atividades específicas: desenvolvimento de recursos, transparência e responsabilidade financeira, ação social, política de formação, recolha de dados, gestão de informação, avaliação de programas, garantia de qualidade.

Figura 5 - Orientações Regulamentares para a Gestão de Caso em Serviço Social Fonte: Adaptação NASW (1992, p. 2-3 2012, p. 15)

O primeiro objetivo da Gestão de Caso de Serviço Social é otimizar o funcionamento e o bem-estar do cliente pela provisão e coordenação de serviços de elevada qualidade, da forma mais eficiente e eficaz possível. No entanto, espera-se que o processo tenha um efeito multiplicador pela abrangência da ação desenvolvida e serviços prestados.

Quanto à natureza da ação que providencia, a GC intervém a nível micro, meso e macro (Figura 6).

\section{PARADIGMAS ORIENTADORES DO MÉTODO DE GC EM SERVIÇO SOCIAL}

A. Serviços centrados na pessoa: $O$ gestor de casos envolve o cliente em todos os processos de GC

B. Primado da Relação Cliente - Trabalhador Social: A relação terapêutica ou o trabalho de aliança entre o gestor e o cliente destina-se unicamente a ajudar este a obter os seus objetivos.

C. Enquadramento Pessoa - Meio Ambiente: O gestor compreende que cada cliente experiencia um influência mútua com o seu meio físico e social, e não pode ser compreendido de forma descontextualizada.

D. Perspetiva das forças: O gestor obtém, apoia e constrói a resiliência e o potencial de crescimento e de desenvolvimento de cada indivíduo. As forças e os recursos podem ser intrapessoais, situados no contexto ou desenvolvidos como resposta ao meio envolvente.

E. Trabalho Colaborativo e de Equipa: O gestor não trabalha de forma isolada, mas em colaboração com outros trabalhadores sociais, outros domínios científicos e outras organizações.

F. Intervenção a nível micro, meso e macro: $O$ gestor utiliza uma variedade de abordagens para produzir mudança nos indivíduos, famílias, grupos, comunidades, organizações, sistemas e políticas. A advocacy desempenha um papel chave. 
Requer que o trabalhador social desenvolva e mantenha a relação terapêutica com o cliente, o que pode incluir a relação que o cliente tem com os sistemas que providenciam e criam serviços, recursos e oportunidades adequados às suas necessidades. Os serviços providenciados podem estar localizados numa única organização ou espalhados por várias agências ou organizações.

A perspetiva das forças (Saleebey, 1996) ganha no processo de Gestão de Caso especificidade:

combining a focus on client strengths and self-direction with other principles: 1) promoting the use of informal helping networks; 2) offering assertive community involvement by case managers, and 3) emphasizing the relationship between client and case managers (Brun e Rapp, 2001, p. 279).

Do ponto de vista processual, podem elencar-se como funções transversais (Figura 7):

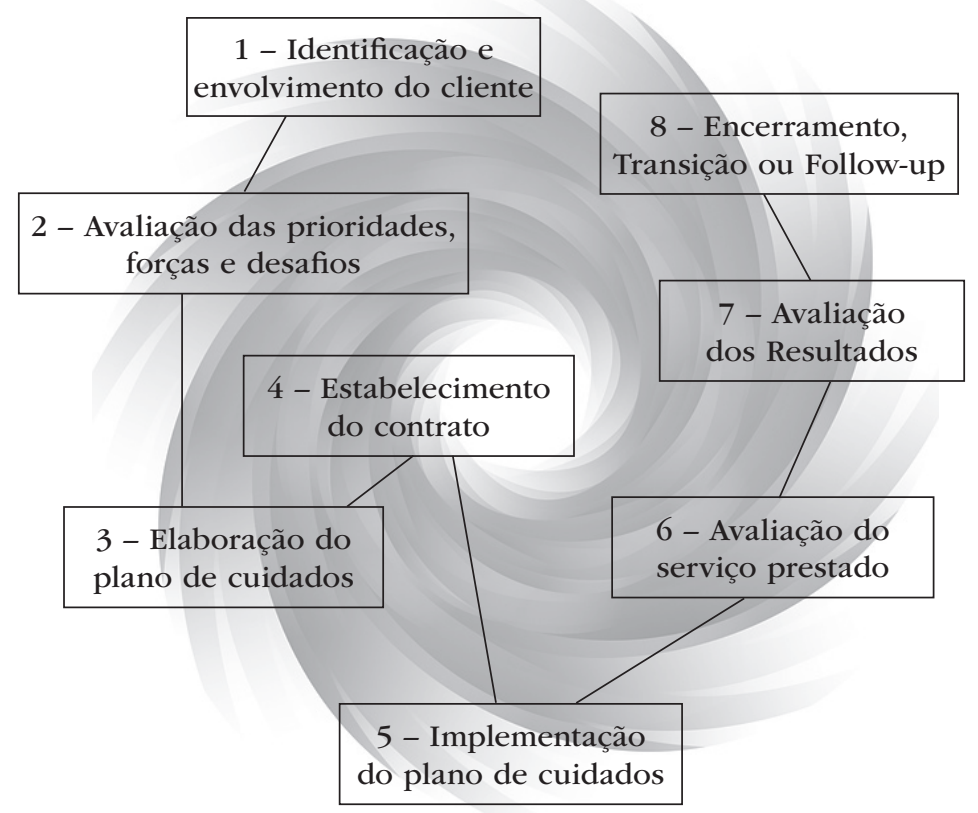

Figura 7 - O Processo de Gestão de Caso (Construção da autora) 


\subsection{3 - O Modelo de Redes: Potencialidades e limites no domínio da Gestão de Caso}

Os anos 80 são caracterizados pela emergência de um novo paradigma de atuação, expresso em diversos movimentos, de onde despoletou o Modelo de Redes, também conhecido por Public Gouvernance, que se caracteriza por 5 macro-tendências: 1 - A presença de instituições e atores para além das governamentais; 2 - o desvanecimento das fronteiras e responsabilidades entre setor público e o não governamental; 3 - As novas relações de poder entre as instituições; 4 - A crescente autonomia e autogovernação de redes de atores, e 5 - o uso de novpos instrumentos e técnicas de provisão de bens e serviços (Stoker, 1998, p. 18, in Cardim, Mota e Pereira, 2011, p. 531). O Modelo de Redes centra-se nas diferentes formas que assume a interação entre as organizações na persecução dos melhores resultados, e neste contexto, o trabalho de colaboração ou em equipa torna-se incontornável e necessário ao envolvimento de diversos stakeholders, mas ao mesmo tempo constitui um desafio permanente. Daqui ressalva a importância da Gestão de Redes.

Kickert e Koppenjan (1997, p. 53) consideram a existência de duas estratégias distintas (a "gestão do jogo" e a "estruturação da rede"), cada uma comportando diferentes atividades:

1 - A Gestão do Jogo que inclui: a Ativação da Rede, a Sua organização, Corretagem (brokerage); Facilitação de relações; Mediação e Arbitragem de conflitos; 2 - A Estruturação da Rede que aloca: o exercício de influência a nível da formulação da política, das relações interatores, dos valores, normas e perceções; a Mobilização de novas coligações e a Gestão do caos.

Contudo, e ainda que tendo por base estas preocupações, a colaboração entre atores não é tarefa fácil, podendo registar-se dificuldades em alguns contextos. São de salientar os fatores-chave sistematizados por Maria Engrácia Cardim, Luís Mota e Luisa Pereira (2011, p. 534) para o sucesso do Modelo de Redes: - Enfoque estratégico muito claro - Liderança e apoio 
estratégico • Criação de um ambiente de confiança • Capacidade de cooperação e mutualismo • Orientação para os outcomes, em detrimento dos outputs.

A dimensão política deste modelo, pela conceção estratégica que integra, a condição de liderança que exige, a dinâmica de cooperação e o referencial da comunicação que subentende e a orientação para os resultados (mudança) que explicita e não para os recursos mobilizados constitui um valor acrescentado de potencial inovador no processo Gestão de Caso, com especial interesse para a dinâmica no projeto profissional do Serviço Social.

Segundo Beulah Compton e Burt Galaway (1998, p. 367) uma das funções do Serviço Social consiste em coordenar a rede de suporte social formal, o que implica prestar apoio aos clientes na identificação das suas necessidades e pedidos, na determinação dos serviços disponíveis na comunidade e assegurar o apoio formal solicitado. É esta coordenação, mais do que a prestação de serviços diretos, que é associada à gestão de casos.

Case management varies in form and function according to the system within which it is developed but the central theme of case management is that responsibility for meeting the needs of the client is with one individual or team whose purpose is to link the client with services required for a successful outcome (Franklin, Solovitz, Mason, Clemons \& Miller, 1987, p. 678).

A GC constitui uma estratégia, na medida em que enquadra um conjunto de meios-fins orientados para o equilíbrio ou para a mudança individual ou familiar, tendo como meta o bem-estar do utente, mas é igualmente um processo de intervenção e gestão ancorada na participação, na articulação de serviços, na intervenção em rede e em equipa, um modelo centrado nas pessoas e nas forças, onde a coordenação colaborativa e a comunicação ocupam um lugar de destaque, em prol de uma maior eficiência e eficácia dos serviços e melhoria do bem-estar e qualidade de vida do utente e do seu sistema de apoio. Pode apresentar configurações diferentes consoante os sistemas em que se desenvolve, mas exige sempre uma intervenção e poder partilhados. 


\section{2 - Mediação: Categoria analítica, da conceção de resolução de conflitos a modelo de intervenção identitário de Serviço Social}

O constructu de mediação está inscrito nos modos de resolução alternativa de conflitos, e é muitas vezes abusivamente confundido com outros processos como a conciliação, a negociação e a arbitragem, apesar de ser deles distinto. Como um modo extrajudicial de resolução de conflitos, expandiu-se por vários campos e domínios temáticos, sendo hoje considerado um processo voluntário, onde a imparcialidade e a neutralidade do mediador (a terceira pessoa, exterior à relação entre os litigantes, que interfere por solicitação dos mesmos) constituem condições que favorecem a comunicação e o estabelecimento de um entendimento fora da lógica ganhador-perdedor, associada à tradicional e judicial forma de resolução dos conflitos. Inicialmente centrada sobre o conflito, e no esgrimir de argumentos que opõem os litigantes, num processo de negociação assistida facilitadora da análise e ponderação de oportunidades de resolução sem dar a face, o conceito de mediação e o processo operativo e reflexivo subjacente foi transitando de uma perspetiva curativa ou preventiva (Modelo de Harvard, Tradicional-Linear de Fisher y Ury, 1998) para uma perspetiva, construtora e restauradora de laços sociais, imprimindo à mediação uma dinâmica transformadora na forma de pensar e de agir. Hoje podem identificar-se três escolas no domínio da mediação de Conflitos: A Escola de Harvard, centrada no conflito/problema (Fisher y Ury, 1998), A Escola Transformativa centrada no processo (Bush e Folger, 1994; Folger 2007), a Escola Circular-narrativa centrada no conteúdo (Sara Cobb, 1997).

O domínio social não podia fugir a esta lógica. Nos Estados Unidos emerge a preocupação com a produção de padrões de qualidade desta prática em Serviço Social (IASW, 2002) não sendo retomada após essa data. Embora se afirme a mediação como um método de Serviço Social, os padrões de qualidade circunscrevem-na a uma abordagem redutora, que não integra a perspetiva holística e de compromisso com a mudança, assente na participação e no valor da equidade, justiça social e da cidadania.

Da análise do documento disponibilizado on-line, salientam-se as seguintes características, que têm subjacente uma conceção de mediação estritamente confinada à resolução de conflitos (Figura 8). 
Princípios da Mediação

1. Mediação - um método de Serviço Social. Mediation is a method of social work practice.

2. Responsabilidade perante o sistema das partes envolvidas no conflito. The mediator is responsible to the system of parties involved in the dispute or decisionmaking process, rather than to any single party or client.

3. Respeitar o Código Ético do Serviço Social. These standards are to be interpreted within the ethical base and values explicated in the NASW Code of Ethics.

4. Possuir Formação e experiência em Mediação e Resolução de Conflitos. Mediators should be familiar with and trained in the theory and practice of mediation. In addition to social work education, the social work mediator needs specific training and practice experience in mediation and conflict resolution.

\section{Responsabilidade Ética} e Profissional. Social work mediators should be accountable, both to the client and to colleagues, for the professional and ethical application of their skills and service delivery.

\section{Revisão regular dos} standards. Because mediation is a growing and developing field, these standards should be reviewed regularly to incorporate new developments in the theory and practice of mediation.
Standards de Prática do Mediador

\section{Standard 1. Ética e Responsabilidade}

Social work mediators shall function within the ethics and stated standards and accountability procedures of the social work profession.

\section{Standard 2. Imparcialidade e neutralidade}

Social work mediators should remain impartial and neutral toward all parties and issues in a dispute.

\section{Standard 3. Confidencialidade}

The social work mediator shall not reveal to outside parties any information received during the mediation process.

Standard 4. Avaliação da adequação da mediação ao conflito Social work mediators shall assess each conflict and shall proceed only in those circumstances in which mediation is an appropriate procedure.

Standard 5. Cooperation in a voluntary and informed basis The social work mediator shall seek at all times to promote cooperation, to prevent the use of coercive tactics, to foster good-faith bargaining efforts, and to ensure that all agreements are arrived at on a voluntary and informed basis.

\section{Standard 6. Saber parar o processo}

The social work mediator shall recommend termination of the process when it appears that it is no longer in the interest of the parties to continue it.

\section{Standard 7. Estabelecimento de um entendimento}

The social work mediator is responsible for helping the parties arrive at a clearly stated, mutually understood, and mutually acceptable agreement.

\section{Standard 8. Compromisso escrito}

The social work mediator shall develop an unbiased written agreement that specifies the issues resolved during the course of mediation.

\section{Standard 9. Possuir formação específica em Mediação}

Social work mediators shall have training in both the procedural and substantive aspects of mediation.

\section{Standard 10. Definição precisa de uma taxa}

A social work mediator shall have a clearly defined and equitable fee structure.

\section{Standard 11. Confidencialidade da informação obtida}

The mediator shall not use any information obtained during the mediation process for personal benefit or for the benefit of any group or organization with which the mediator is associated.

Standard 12. Trabalho colaborativo com outros profissionais Social work mediators shall be prepared to work collaboratively as appropriate with other professionals and in conformance to the philosophy of social work and mediation. 
O documento não produz qualquer referência ao enquadramento da mediação na história do Serviço Social, nem posiciona o pensamento crítico no devir desta abordagem no âmago da intervenção dos trabalhadores sociais, limitando-se a constatar a existência de um número crescente de profissionais com desempenho nessa área, sobretudo a nível familiar.

Hoje a mediação social é mais do que um vocábulo partilhado, é uma forma de equacionar a procura de soluções, negando o modelo de deficit que tem minado a intervenção social durante décadas em todos os continentes e que mais não tem do que contribuído para a perpetuação dos conflitos e dos problemas sociais. A este propósito Loncle (2001, p. 82) refere que

l'apparition de ce référentiel d'action (en parlant de la médiation) traduit la reconnaissance du fait que l'appropriation des normes par les individus ne passe plus par la stricte imposition de celles-ci mais requiert leur adbésion, ce qui suppose une démarche ative, d'échange, (...).

Se é verdade que, o quadro do referencial de ação designado por mediação, não compagina com a imposição de regras sem adesão dos seus destinatários, através da promoção de trocas e da sua participação ativa nos processos, a ausência de formação adequada, a incerteza do futuro de todos os que a ela se dedicam, a diminuição dos resultados no terreno, são argumentos esgrimados contra o estabelecimento definitivo da mediação no setor social (Abdellaoui, Auzoult, Reggad et Roy, 2010)

\subsection{1 - Mediação = Categoria Reflexiva e ontológica}

Com inicio na segunda metade dos anos setenta do século XX e desenvolvimento na década de 80 , o estudo da problemática da mediação em serviço social acompanhou o amadurecimento da reflexão sobre as orientações teóricas e operativas de intervenção, passando a ser objeto de interesse em pesquisas efetuadas no continente americano e europeu. Enquanto categoria 
reflexiva ${ }^{1}$, a mediação está presente no estudo das determinantes socio-históricas e culturais da sua evolução, no aprofundamento dos procedimentos metodológicos, na procura das suas interdependências com as políticas sociais e tem-se revelado como um sinalizador ativo na compreensão da exigência de intervenção social para e na mudança. No entanto, a produção científica no domínio da mediação como categoria ontológica é escassa e pouco fundamentada nas práticas quotidianas profissionais, sendo abordada apenas na forma abstrato-formal da imediaticidade ou através das representações de profissionais, pelo que, como afirma Reinaldo Pontes "O Assistente Social pode atuar na perspetiva da articulação de mediações, mas a ausência de investigações sobre a prática não permite demonstrá-lo” (1995, p. 183).

Para Vicente Paula Faleiros a prática profissional contém "saber estratégico" e "saber tático", um "saber que necessita de se situar num contexto político global e num contexto institucional particular, visualizando as relações de saber e poder da e com a própria população [...] um processo de redescoberta de mediações" (1985, p. 28). Para o autor a mediação apresenta dois sentidos concomitantes: um que considera os movimentos sociais como mediações face às políticas sociais e outro que coloca as mediações como produtos da ação profissional. "As mediações são construções de categorias que permitem a análise complexa de situações concretas. A transformação social é um processo de mediações complexas e não só oposições rígidas" (ibidem, 94). Apresentam-se, assim, duas conceções de mediação: uma como categoria de análise da realidade e outra como componente de ação de transformação social, uma categoria operativa, estratégica para a ação. A aliança e o confronto localizam-se no campo das estratégias e táticas úteis à solução de problemas, pela modificação das relações de força existentes. Este posicionamento implica a criação de formas de comunicação horizontal baseada no diálogo entre o Assistente Social e a população. Como categoria de análise indica que nada é isolado, nada é autónomo, a mediação é uma relação histórica.

\footnotetext{
1 As categorias, para efeito do processo de conhecimento, são de natureza ontológica e reflexiva. Quando são recriadas pela razão a partir do real estamos na presença de categorias ontológicas. Se expressam "formas de ser", que se constituem em estruturas lógicas criadas pela razão, ligadas predominantemente ao imediato (cf, Lukács, 1979, 90 in Pontes, 1995) e descontextualizadas historicamente, são categorias reflexivas.
} 
Aldaísa Sposati (1985), investigadora brasileira, após um percurso de reflexão sobre a mediação em Serviço Social, levantando questões sobre o papel do Assistente Social na relação capital-trabalho, e sobre os instrumentos e técnicas utilizadas, conclui que o termo era utilizado de um modo confuso e pouco claro. Entre as suas posições destaca-se a defesa da mediação-assistência como fundamental Serviço Social. Fazendo a análise histórico-reflexiva da mediação em Serviço Social, Reinaldo Pontes corrobora este posicionamento:

O assistencial como mediação fundamental trazia a categoria da mediação como âncora analítica que possibilitaria a ultrapassagem metodológica e política das conceções precedentes de assistência, porque trouxe uma componente de negação da imediaticidade da ação assistencial tradicional" (1995, p. 112).

Como mediação fundamental, a assistência ocupa um lugar de passagem incontornável e necessário para uma prática profissional transformadora. Ela é fundamental ao progresso da consciência e apropriação de bens e serviços por parte das "classes subalternizadas". Deste modo, o Serviço Social assume uma dimensão política, na medida em que o Assistente Social trabalha com e nas mediações, ele não é apenas o executor de mediações. A conceção que considerava que fazer mediação significava ficar entre os interesses da população utente dos serviços sociais e os interesses institucionais, como traduz a posição de William Schwartz (1976, 1984), é, pois, questionada.

Com efeito, para este autor o trabalhador social tem a responsabilidade de ajudar tanto o cliente como a instituição: por um lado, deve ajudar cada cliente individual a resolver o seu problema imediato através da instituição, e, por outro lado, deve ajudar a instituição a chegar até ao cliente, oferecer os seus serviços e deste modo cumprir a sua função na comunidade. Mas ressalva que a função do Trabalhor Social é a de ser o mediador nas transações entre as pessoas e os diferentes sistemas (família, grupos, instituições sociais, bairro, escola, trabalho, ...), sabendo que a mediação não visa criar harmonia mas interação. Schwartz (1976), defende que a identificação profissional advém do ponto de convergência das necessidades do indivíduo e da sociedade, ou seus sistemas e subsistemas. Este modelo reconhece que existem momentos em que as complexidades do envolvimento são de tal 
ordem, que as instituições têm dificuldade em assegurar os seus serviços, e o cliente pode também ter dificuldades na sua utilização. Ora, é precisamente a nível da implicação entre cliente e instituição que é necessária a mediação do trabalhador social. Neste sentido, o trabalhador social identifica-se com o serviço que o organismo presta e a necessidade do cliente, centrando o seu esforço na satisfação dos interesses mútuos fundamentais. $\mathrm{O}$ autor acrescenta ainda a idéia de que a função do trabalhador social na instituição é análoga à função que esta assume quando se coloca entre o cliente e a comunidade. Partindo desta base, Schwartz (1984) propõe um modelo de mediação aplicado ao Serviço Social de Grupo: Define sob o plano funcional o trabalho profissional, sob o prisma do postulado da "relação simbiótica" que estabelece entre o indivíduo e a sua cultura de origem. Propõe que o trabalho profissional sirva de mediador no processo em que o indivíduo e a sociedade estão envolvidos quando pretendem responder a uma necessidade. O modelo de mediação aplicado ao trabalho com grupos engloba atividades específicas (tarefas) em qualquer que seja o sistema-cliente, valorizando as técnicas de interação (cognitivas e transitivas). Com a incorporação da mediação na discussão metodológica, o campo de intervenção passou a ser percebido como um campo de mediações e, dado que o campo interventivo é um todo complexo e relativo, a mediação ganha contornos de centralidade no plano da análise e no plano da intervenção.

Para além dos autores latino-americanos, e anglo-saxónicos, outras contribuições surgiram no campo da mediação em Serviço Social no contexto europeu. Jaudon (1982) considera que o Assistente Social concilia o possível e o desejável, quando adapta as decisões administrativas às necessidades dos utentes. As instituições gerem o possível (orçamentos, equipamentos, prestações, direitos) e os Assistentes Sociais apreendem o domínio do desejável (ajudam na análise da situação, avaliam as necessidades, estabelecem em conjunto um projeto que tenha em consideração as capacidades e as potencialidades oferecidas pelos serviços). Porém, conforme mostra o autor numa pesquisa que fez (seis casos durante seis meses) apenas em 39\% das situações este tipo de mediação teve resultado. A sua eficácia foi reduzida. Face a esta constatação, define a mediação como uma alternativa ao conflito, que apresenta as seguintes características: a) a ajuda é um espaço 
de poderes antagonistas, uma vez que existem dificuldades em conciliar o poder técnico do mediador e o poder administrativo dos responsáveis financeira e juridicamente pelas ações desenvolvidas; b) a mediação é uma interceção - esta representação está presente quando alguém procura do Assistente Social como aquele que identifica a necessidade, que é competente para a enunciar, fazer compreender e obter aquilo que o sujeito sozinho não poderia alcançar. Embora seja um profissional regra geral sem poder de decisão, o Assistente Social tem acesso a quem o detem e por isso pode encontrar a resposta para o problema. O profissional constitui um suporte técnico que cria a possibilidade de o utente se tornar ator de novas relações; c) a mediação é uma interpelação - quando o conflito se localiza e provém do "mau funcionamento da sociedade", o Assistente Social é solidário com aquele que solicita apoio, ajuda-o a analisar as envolventes do problema, assumindo um papel de agente com capacidade de fazer a leitura do fosso que existe entre o discurso e a prática e de canalizar essa análise para os utentes e instâncias de decisão. Assume, deste modo, um papel de analista social que não se limita a constatar, a regular problemas concretos, mas que coloca novos problemas (Geng, 1977, apud Jaudon, 1982); d) a mediação é manipulação - quando o Assistente Social se esconde na rigidez normativa e na sua posição de executante, num processo de adaptação dos utentes à instituição em que trabalha, influenciando diretamente a tomada de posição daqueles em conformidade com as orientações institucionais.

Também Cristina de Robertis (1981) no quadro da abordagem do Serviço Social enquanto método e processo, sistematiza o modelo de intervenção alternativo ao modelo clínico. Esse modelo de intervenção baseia-se em quatro elementos: na conceção de trabalhador social como "agente de mudança", no projeto de intervenção que define os objetivos e meios da ação e no confronto de projetos dos diferentes intervenientes (trabalhadores sociais, clientes e organismo empregador), levando à construção de um projeto comum. Da relação destes três elementos nasce o quarto elemento-chave, que é a estratégia. É neste contexto que a autora afirma que falar de intervenção equivale a "querer agir", "prendre part volontairement, se rendre médiateur, interposer son authorité". Este é o sentido prático da intervenção do trabalhador social, e é ele que orienta todo o processo metodológico proposto pela autora. 
Também aqui a mediação assume uma posição central na compreensão do saber fazer e saber ser profissional.

\subsection{2 - Mediação Social $=$ um modo de regulação social e de reconfiguração} dos laços sociais

Os anos 90 do século XX constituem um período de renovação conceptual e simultaneamente um período de proliferação da prática de mediação. $\mathrm{Na}$ continuidade dos princípios originários das "Boutiques de Droit", que se resume, por um lado, em facilitar o acesso ao direito e, por outro lado, enquadrar dinâmicas de mudança comunitária no processo de resolução de pequenos litígios e problemas sociais. A mediação, sobretudo aquela que se desenvolve em contexto comunitário e com um devir social, deixa de ser unicamente um modo alternativo na resolução de conflitos e passa a ser um instrumento conceptual e operativo na composição e restauração de laços sociais, uma conceção útil em processos de luta contra a discriminação e exclusão social.

Nesta linha de pensamento e no domínio do Serviço Social, salientamos os contributos de Marie-France Freynet (1996) cuja obra central é Les médiations du travail social - contre liexclusion, (re)construire les liens, e Dominique Bondu (1998) com o livro Nouvelles pratiques de médiation sociale. Jeunes en dificultés et travailleurs sociaux. Freynet afirma o papel mediador do Trabalho Social na restauração do laço social e da cidadania (ibidem, 280), através do desenvolvimento de redes de socialização dos excluídos. Informar sobre os direitos, as possibilidades e constrangimentos institucionais, dar a conhecer as suas necessidades e negociá-las coletivamente com os responsáveis políticos ou administrativos são competências profissionais que facilitam o exercício da cidadania e a recuperação ou instauração de laços sociais, sem tomar para si um papel relevante. Ele é um ator profissional implicado no jogo social que opera entre os excluídos e a sociedade instituída, entre os excluídos e as redes e entre essas redes e as instituições. Neste sentido, a mediação visa reestabelecer transações nos elos em que não existe comunicação. A autora esclarece ainda o processo metodológico da mediação do Trabalho 
Social, que inclui as seguintes etapas: apoiar as potencialidades dos excluídos, apoiar as potencialidades do meio (a carta partenarial), construir a utilidade social contra a exclusão e fazer a avaliação com todos os atores envolvidos.

Marie-France Freynet (1996) estabelece um conjunto de modelos de mediação para o Trabalho Social a partir da análise de práticas a nível da interação que se estabelece entre a pessoa e o meio. A cada tipo de interação a autora associa uma conceção de intervenção social bem como a descrição dos objetivos e dos métodos de intervenção. Estabelece deste modo quatro abordagens:

1 - A Abordagem Analógica - que coloca o trabalhador social numa situação de exterioridade em relação ao problema colocado pelo utente, competindo-lhe avaliar a situação e proceder á atribuição de recursos existentes, de forma pontual. Segundo esta abordagem o profissional é um executante de orientações pré-definidas, sendo condição de sucesso a análise do problema (elementos estáveis da personalidade e do meio), o conhecimento dos recursos existentes e a conexão e reavaliação periódica. Em consequência deste tipo de mediação surge a dependência e a estigmatização do utente. A mediação exerce-se junto do polo institucional.

2 - A Abordagem Relacional - que se baseia num processo de interação simples entre a pessoa e o meio. O trabalhador social é um especialista da relação, mas mantém uma posição de exterioridade em relação ao problema, apesar de tentar manter-se equidistante do polo institucional e do polo pessoal. O utente é considerado uma pessoa em relação e o trabalhador social facilita e regula as trocas. Este tipo de mediação desenvolve a capacidade relacional dos sujeitos consigo próprios e com os outros. Para implementar esta abordagem é necessário que o profissional conheça as suas capacidades de interação e de influência, possua a capacidade de proceder ao diagnóstico da situação e consequente capacidade de negociação e intervenção através da entrevista de ajuda. A abordagem relacional permite identificar as variáveis relacionais mais significativas para o sujeito e para a superação da situação-problema.

3 - A Abordagem Orgânica - permite captar os processos de interação recíproca que são complexos, permanentes e situados no tempo. O trabalhador 
social apoia-se na análise sistémica e intervem a nível grupal, através de um processo de animação. A sua mediação apoia o desenvolvimento de laços sociais e a construção de projetos. Segundo esta abordagem o utente é um ser que se projeta no futuro, que possui capacidades para progredir na construção e implementação do seu projeto de vida. O trabalhador social avalia essa capacidade, facilita a formação e a organização coletiva. Este trabalho viabiliza a identificação das interações existentes entre a pessoa e o meio ambiente numa dimensão temporal de presente e futuro.

4 - A Abordagem Transacional - que integra processos de exploração temporal da potencialidades e limites. Sensível aos movimentos contextuais globais, ela é complacente com a ambiguidade daí resultante, permitindo descobrir o imprevisto, torná-lo criativo em termos de espaços e meios de vida específicos. O princípio da não determinação dos fenómenos permite o desenvolvimento de uma capacidade de leitura global, de ação criativa, e consequentemente de mudança. O trabalhador social abandona a sua posição de exterioridade em relação aos problemas, ele adota uma postura implicada, apoiada nas capacidades dos atores, que possibilita a mobilização de sinergias e o trabalho de projeto. Segundo esta abordagem, o profissional através desta mediação favorece a tomada de consciência, permite a auto-organização para uma ação de nível socioeconómicopolítico e impulsiona o exercício da cidadania. Reconhece que o utente está consciente das relações sociais que mantém, suas potencialidades e limites, e procede com ele a uma análise multirreferencial potenciadora da emergência do novo e com ele a mudança.

Dominique Bondu (1998) considera que a prática de mediação social tem por finalidade a reconstrução de uma dinâmica individual e coletiva, necessária ao processo de procura social. Através da mediação os sujeitos adquirem a possibilidade de se reprojectarem no tempo e no espaço, dando corpo aos respetivos projetos de vida. "O trabalbo de mediação social consiste em transformar as lógicas tradicionais dos atores do campo social, designadamente as conceções dominantes de inserção" (Ibidem, p. 98). Tal exige o estabelecimento de uma relação de companheirismo entre o interventor e os sujeitos, para além de uma atitude de escuta e de plena disponibilidade, uma escuta que não seja seletiva nem orientada por parâmetros da ação institucionalizada. 
O domínio da mediação em Serviço Social está em construção, numa relação quotidiana entre procura e oferta, contexto socioinstitucional e competências profissionais.

O contributo destas autoras neste domínio é relevante mas não permite captar o caráter dinâmico da mediação dos trabalhadores sociais. E isto por três motivos: Em primeiro lugar, trata da mediação em Trabalho Social com a polissemia que o termo inclui: não se distinguem diferenças entre os vários profissionais incluídos no grupo. A nomenclatura de trabalhador social abrange uma ampla diversidade de profissionais e a

"L'autodésignation comme travailleur social, la quête d'un statut et donc d'une légitimité sont fréquentes là où ne sont pas nettement définis les postes de travail, les intitulés de métiers, la rélation entre postes de travail et titres scolaires, c'est-à-dire dans les zones où apparaissent de nouvelles catégories de travailleurs sociaux ou qui sont investies depuis peu par des travailleurs sociaux" (Ion e Tricart, 1998, p. 23)

Isto torna a questão ainda mais complexa. Todas as práticas poderão ser entendidas como mediações? As diferentes abordagens identificadas por Freynet (1996) estão presentes em toda e qualquer prática de qualquer trabalhador social? Em segundo lugar, apesar de serem consideradas as questões metodológicas e os objetivos de cada abordagem, cada uma delas surge dissociada da outra e a diversidade dos seus elementos constituintes a nível metodológico é pouco explorada. Por exemplo, a abordagem analógica exclui a entrevista de ajuda? Em terceiro lugar, não mostra como as diferentes abordagens se corporizam na prática dos trabalhadores sociais. Como se articulam as diferentes mediações? Elas são sequenciais? Estão articuladas? Ou cada uma corresponde a um determinado perfil de trabalhador social? Qualquer das propostas enunciadas apresentam limitações que advêm do seu objeto de incidência e da não ponderação dos fatores intrínsecos e extrínsecos que intervêm na complexidade da mediação. A elaboração de modelos não constitui uma meta em si, ela é um degrau no processo de construção do conhecimento que nos permite proceder a análises diferenciadas de uma mesma realidade. 
2.2.3 - Mediação Social = uma conceção holística e integrada de intervenção social, um modelo refundador da identidade profissional

Enquanto modelo de intervenção social, a mediação social profissional implica um conjunto de ações que lhe dão visibilidade e que se forem consideradas de forma singular, independentes e descontextualizadas constituem constantes na diversidade de práticas profissionais no domínio social. O estudo realizado entre 1997 e 2000 (Almeida, 2001) afirma o valor do contexto na construção da ação mediadora e confirma a mediação como uma conceção identitária do Serviço Social e como um modelo de intervenção social. Como salienta Marc-Henry Soulet, no prefácio da obra da autora "Este aspeto da intervenção social tornou-se um dos vetores atuais da legitimação do trabalho social, após períodos mais sombrios de controlo social e os mais (demasiado) cor de rosa da mudança social como modo de representação dos seus objetivos".

O Serviço Social instituiu-se como uma prática profissional de controle e de regulação social, mas tem vindo a afirmar-se tanto em contextos de normalização e integração social, como de luta pela liberdade dos Homens e pela valorização da cidadania, assumindo diferentes perspetivas consoante as características do "locus" interventivo (a nível micro, meso e macro) e o perfil socioprofissional do Assistente Social. A sua posição intermediária nos mecanismos de proteção social tem sido estruturante do seu saber, fazer e ser profissional. Este é um dos motivos porque não se pode falar de Serviço Social sem lhe associar uma função mediadora cujo sentido é necessário explicitar, constituindo um dos desafios a nível conceptual.

"A diversidade de práticas permitiu a identificação de perfis de mediação cujo estudo constitui uma fonte de reflexão sobre a bomogeneidade versus heterogeneidade de procedimentos operativos: esta permite-nos captar uma espécie de modus vivendi profissional e os traços uniformes identificadores de intervenções diferenciadas que estão presentes nas práticas quotidianas. A análise transversal da heterogeneidade no concreto assegura a construção de modelos operativos de mediação profissional e a compreensão da diversidade de sentidos atribuídos a essa prática" (Almeida, 2001, p. 17). 
A figura 9 resume a mediação social como uma conceção global de ação e modelo de intervenção, como um produto construído na interação e como um processo de intervenção, onde se destacam modalidades de ação transversais, orientações estratégicas da ação e competências mobilizadas, em contextos de intervenção diversificados diversificados do setor público e do terceiro setor em domínios como a saúde, educação, segurança social, poder local, ação comunitária, reabilitação e trabalho-emprego, num total de 27 campos e 54 assistentes sociais.

A Mediação em Serviço Social configura-se através de Modalidades de ação - Processos de Intervenção (Prestação de informação, Advocacy, Formação de Competências, Gestão e Administração de Recursos, Encaminhamento Social, Acompanhamento Psicosocial) Estratégias de Intervenção - Orientações meios-fins (Relacionais ou de abordagem, Enquadramento social, Empowerment, Contratualização) e Competências Profissionais (Comunicação, Estudo, Análise, Argumentação, Negociação, Trabalho em Equipa, Intervenção em rede, Planificação, Avaliação).

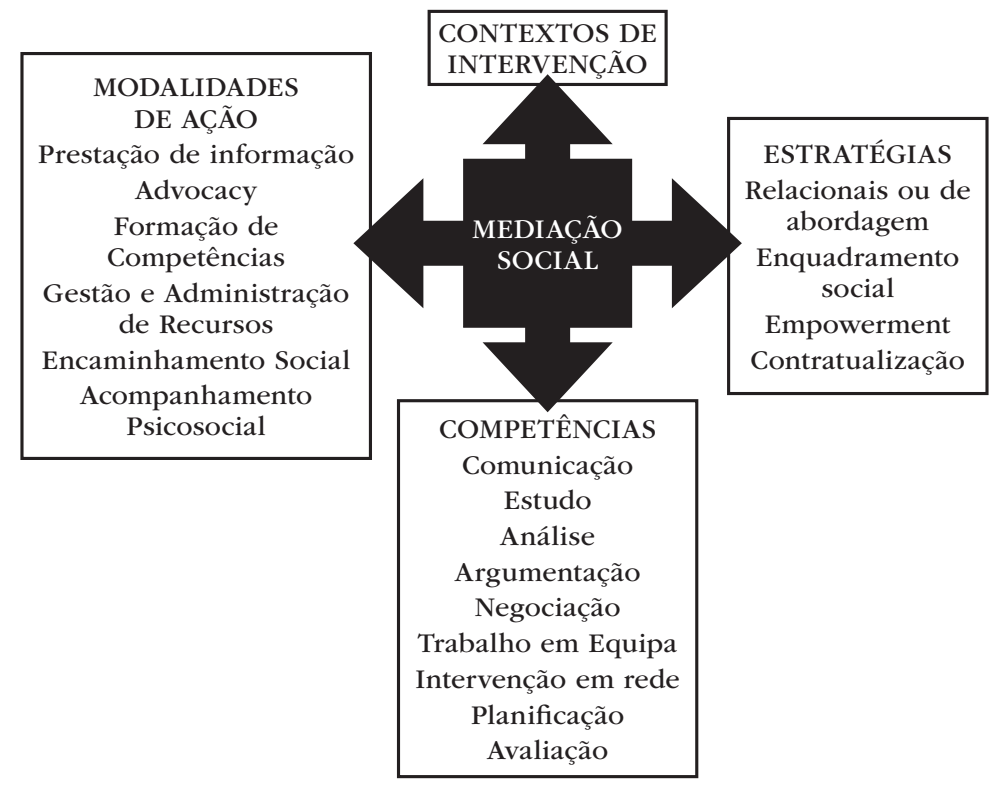

Fig. 9 - Mediação Social: conceção global de ação e modelo de intervenção Elaborado pela autora (2012) 
A Mediação em Serviço Social configura-se através de Modalidades de ação - Processos de Intervenção (Prestação de informação, Advocacy, Formação de Competências, Gestão e Administração de Recursos, Encami-

nhamento Social, Acompanhamento Psicosocial) Estratégias de Intervenção

- Orientações meios-fins (Relacionais ou de abordagem, Enquadramento social, Empowerment, Contratualização) e Competências Profissionais (Comunicação, Estudo, Análise, Argumentação, Negociação, Trabalho em Equipa, Intervenção em rede, Planificação, Avaliação).

Cada um destes aspetos integra conhecimentos teóricos, práticos e valores indissociáveis. Por isso mediar não é para quem quer, mas para quem possui conhecimentos na área e tem sensibilidade social que lhe permita gerir os conhecimentos como recursos adequados à complexidade dos contextos interventivos: 1) a nível micro (indivíduo, família, tipo de procura e redes de apoio); 2) a nível meso (sistemas e serviços disponíveis, satkeholders, dinâmicas relacionais na articulação de recursos) e 3) a nível macro (Legislação, políticas sociais gerais e territorializadas).

\section{Conclusão}

Ser Gestor de Caso em Mediação Social - Ser Mediador Social em Gestão de Caso: desafios e complementaridades na especificidade do Serviço Social

Como refere Reinaldo Pontes (1995) o Assistente Social não é nem uma mediação nem um mediador, ele é um articulador de mediações, no quotidiano daqueles que procuram os seus serviços. Partindo das determinações da vida quotidiana definidas por Lukács (1979), a heterogeneidade permite compreender o "modus vivendi" da população que utiliza os serviços e a imediaticidade promove o recurso aos comportamentos objetivos, padronizados e automatizados, impondo respostas que raramente ultrapassam o aparente. Se o Assistente Social atua ao nível do quotidiano dos grupos excluídos e se a sua mediação permite ultrapassar essa situação, então ele não é um mero mediador, ele é um agente que trabalha com e nas mediações.

Consideradas as unidades de intervenção do Serviço Social o indivíduo, grupo, comunidade, serviços e políticas sociais (Falcão, 1979) e ainda o "locus" 
institucional da profissão, isto é o contexto institucional do exercício profissional (Karsh, 1989; Weisshaupt, 1988), o Assistente social é um mediador com características especiais. Independente do modelo teórico subjacente à sua prática, ele é um mediador que potencia mediações devido à sua posição intermediária nos equipamentos em que se encontra a exercer funções, às competências que lhe estão legalmente e formalmente atribuídas, à autoridade que lhe é reconhecida e às características do projeto profissional.

- A sua posição intermediária nos equipamentos e na aplicação das medidas de política social a nível local: o Assistente social ocupa um lugar de reserva institucional no confronto com os problemas que advêm da forma como a o sistema macro está organizado e da forma como articula as lógicas individuais e coletivas, nas dimensões económicas, políticas, sociais, culturais e ambientais, da aplicação das normas ou das insuficiências institucionais e dos sistemas (indivíduo, família e comunidade). Regra geral, este profissional faz parte do circuito de "interface" da instituição com o meio e com os seus utentes: acolhe e o atende a pessoa e em face daquilo que observa, interpreta as informações disponíveis e o posicionamento do utente face ao problema e traduz o pedido numa forma acessível à instituição e enquadrável nos mecanismos de resposta existentes; Dá seguimento à situação, definindo um plano prévio de intervenção que pode passar pela via assistencial, mas sempre por uma ação a nível relacional. O seu posicionamento intermediário, entre o sistema transformador de recursos e os utilizadores dos serviços (Gaulejac, Bonetti et Fraisse, 1989) ganha visibilidade na análise dos organogramas institucionais. Neste circuito este profissional não é um mero intermediário, é um interlocutor qualificado para identificar as necessidades e os recursos disponíveis ou a acionar para dar uma resposta adequada à situação identificada.

- As competências traduzem práticas quotidianas definidas a partir da imagem que cada profissional produz sobre o seu desempenho profissional face às procuras e solicitações que lhe são formuladas. A definição de competências e funções faz-se por transposição dessa imagem para outras realidades de trabalho e é influenciada pelas características da ação a empreender, pela representação que as chefias têm das necessidades da população e da capacidade de resposta do sistema, bem como do saber fazer e compreender que 
é reconhecido ao profissional. Ora uma das competências profissionais do Serviço Social é a capacidade de escuta e de diálogo implícita à função de apoio e acompanhamento psicossocial que é transversal a todas as práticas, em qualquer campo de intervenção. Neste contexto, o Assistente Social é o mediador que faz a gestão tanto do que é objetivo e observável como das expectativas dos utentes, no quadro de um processo que conduz à construção de respostas ajustadas à situações de vida, necessidades e problemas vivenciados pelos mesmos.

- O papel do Assistente Social é o de criar condições para que a relação se estabeleça ou restabeleça entre as pessoas e entre estas e a sociedade. Fá-lo, criando espaços de troca de informação, fornecendo ou acedendo a nova informação, atribuíndo recursos, providenciando serviços, encaminhando, mobilizando parcerias. E fá-lo de forma formal e informal, mas é sobretudo no quadro institucional e na articulação com os indivíduos, as famílias, as redes de apoio, os stakeholders na comunidade, que exerce essa função. Por isso ele é um mediador institucional e profissional: institucional tendo em consideração o "locus" de partida da sua intervenção e o espaço de fronteira que ocupa entre a administração e os utentes, e profissional perlo perfil que lhe é reconhecido de intermediação na relação entre os indivíduos e entre estes e as instituições, sempre que ocorram conflitos de interesse ou dificuldades no acesso, através da ação direta ou da Advocacia Social (Social Advocacy).

Bernard Goudet (1989) atribui aos trabalhadores sociais a posição de “marginais secantes”, situados à margem do sistema decisório. Para este autor, o desenvolvimento do exercício profissional processa-se na interseção do campo das condições e das práticas de vida quotidiana das populações com o campo de orientações de ação a desenvolver, seja ela compensadora ou corretora. "Os trabalhadores sociais encontram-se na interseção do campo das instituições mandatadas para a realização das orientações da ação social e do campo da tecnicidade profissional mobilizada do ponto de vista instrumental para a ação concreta" (1989, p. 34). Assumem deste modo, um lugar de "semiexterioridade", um papel de "passador de fronteira", como refere Henri Desroches (1974). Porém, como mediador os Assistentes Sociais são agentes de mediações, um "linking agent", como refere Lambert Maguire 
(1989, apud Sanicola, 1994, p. 52), dado que o seu papel consiste em assegurar a relação entre o cliente e os sistemas de ajuda. O Assistente Social é um elemento "mobilizador e coordenador de recursos informais da comunidade", ele assume um papel de elo de ligação que propicia a emergência de mediadores cidadãos, no quadro de associações, ou pela implicação de "mediadores desconhecidos" (Six, 1990) cujas funções se exercem no quotidiano das famílias e das populações.

- A nível operativo a sua ação é "centrada no outro", muitas vezes com um registo diplomático de imparcialidade. Dependendo do grau de autonomia dos sujeitos e dos contextos normativos e organizacionais da intervenção, e do ponto de vista dos princípios norteadores da sua ação profissional, a Assistente Social raramente substitui o utente, competindo-lhe criar condições para que seja o utente a definir claramente a sua posição no processo de solução do problema, ocupando uma posição de retaguarda, reconhecendo que a sua intervenção constitui uma variável a considerar no processo de mudança esperada, mas não requer para si um papel preponderante. Ele age de forma indireta, informando, confrontando os sujeitos com as situações de vida e com as posições de cada uma das partes, em caso de conflitos, criando espaço para a emergência do novo. No decurso da sua intervenção espera-se que ocorra um salto qualitativo na relação entre as partes envolvidas (entre membros da família, entre vizinhos, entre utente e organização, entre organizações e entre organizações - utentes e comunidade) e, em consequência disso, no processo de transformação da situação inicial. A troca de pontos de vista, o conhecimento dos recursos, a análise dos aspetos positivos e negativos das suas posições por referência aos objetivos pretendidos, permite promover mudanças pela via da interação. Apenas o processo interativo dos diferentes elementos na ação (as partes entre si e com o interlocutor / mediador) centrado na pessoa e nas oportunidades e nas forças permite a prevenção de conflitos ou comportamentos marginais, a promoção de atitudes positivas face à situação e à mudança, e a procura de uma saída que, não sendo aquela que o utente preconizava ou solicitava na fase inicial, acaba por traduzir-se nos termos do acordo e do compromisso estabelecido em plena liberdade de opção.

Isso constitui “missão impossível”, dirão algumas pessoas, "difícil...", dirão outras, "missão exigente em recursos humanos, materiais e temporais" 
afirmam muitos, "com políticas coerentes e ajustadas aos princípios da vida democrática" acrescentamos. Como compatibilizar tais requisitos profissionais, quando as exigências processuais são de larga monta? Quando as regras mudam a uma velocidade atroz e os conflitos se adensam, os direitos se vão esfumando e os valores, que deveriam ser uma constante na vida, se esgueiram?

- Apesar de não ter poder decisório, o Assistente Social possui autoridade que reflete o reconhecimento da sua capacidade para intervir na situação, para apoiar o processo de escolha, proposta ou construção de uma alternativa no processo de solução para situações conflituosas, porque problemáticas. Embora nem todas as ações empreendidas por ele sejam enquadráveis no perfil de mediação nem no da Gestão de Caso, o seu desempenho é tendencialmente evolutivo e faseado desde a assistência ao fortalecimento do poder dos sujeitos, necessário à adoção de um posicionamento ativo no seu próprio desenvolvimento e na construção e implementação do seu projeto de vida. Comum a estes modelos está a sua dimensão estratégica, embora essa possa ser mais discursiva do que real. Estratégica do ponto de vista de quem? Do sistema, do profissional ou do utente? Do sistema certamente será: tanto a gestão de caso como a mediação possuem uma dimensão política que não se pode escamotear e que já foi analisada. A visão de controlo que lhes está subjacente funciona como um amortecedor dos problemas sociais. Mas tanto um processo como o outro integram uma dupla função: gerir de forma coordenada os sistema de prestação de serviços para assegurar que os mesmos sejam mais eficientes e produzam maior bem-estar, solucionar problemas tendo a comunicação como elemento estruturante. Uma boa opção, poder-se-á pensar. Mas tem um senão, o controlo produz-se no sentido dos profissionais, dos utentes e dos serviços, mas o controlo dos custos acaba por escapar à lógica da racionalização, eles aumentam com a utilização dos serviços. Esta dimensão económica, plenamente compatível com a qualidade, implica bons e eficientes gestores, com formação adequada e capacidade de liderança. A subalternização da profissão a poderes decisórios distantes das dinâmicas relacionais entre oferta e procura social, afastados das dinâmicas societais territoriais, acompanhada pela ausência de formação na área da gestão dos profissionais a quem é atribuída a função de gestor de caso ou de mediação social, faz com que se verifiquem incompatibilidades processuais. Para maior controlo, exige-se mais informação; para 
se produzir mais informação, desvaloriza-se o trabalho relacional fundamental ao exercício profissional competente. Mobilizar parcerias, articular recursos, promover empowerment (aumento de poder e capacidade de decisão a nível individual, organizacional e político) exigem tempo, e o período que vivemos é de urgência e emergência social. O envelhecimento da população, o desemprego, o endividamento das famílias, as situações de risco e de perigo social, a pobreza colocam desafios às organizações e aos profissionais, e exigem respostas imediatas, alocando em segundo plano outras exigências, como a de responsabilidade social, a de transparência processual, de participação cidadã, de cooperação interinstitucional, de construção de alternativas sociais num diálogo permanente entre recursos (materiais, humanos e financeiros) e serviços providenciados a nível dos vários sistemas sociais. A questão adensa-se quando se reconhece a exigência de intervenções inovadoras adequadas às novas demandas sociais.

Se do ponto de vista concetual a Gestão de Caso e a Mediação apresentam características e processos distintos mas complementares, a conceção de Mediação Social alarga o horizonte de entendimento do Serviço Social pela diversidade de processos que operacionaliza, pelo largo espectro da intencionalidade da ação que aloca e pela perspetiva de futuro que potencia. Mas também neste processo, que assenta na comunicação e na mudança, por ser lenta e dificilmente mensurável, acaba por apresenta as mesmas limitações que a GC e que são estruturais. Tal não significa que não se lhes reconheçam potencialidades no plano da intervenção individual, familiar e societária. Sobretudo tem de se apostar na formação, na investigação e na reflexão. Qualquer dos modelos de intervenção exige formação específica, e essa tem de ser regulada, no sentido de perspetivar requisitos que se situam para além dos conteúdos formativos e permitam responder às questões: O que é um gestor de caso competente? O que é um mediador social competente?

\section{Bibliografia}

Abdellaoiu, S; Auzoult, L; Reggad, K et Roy, P (2010). La médiation sociale: un champ professionnel toujours en quête d'identitéSocial mediation: a professional field in search of identity, Les C@biers de psychologie politique, 16

Abreu, M. (1978). Tarefa fechada e tarefa aberta, Coimbra, Ed. do autor. 
Adams, R. (2008). Empowerment, participation and social work. BASW Practical Social Work. Series Editos, Jo Campling. $4^{\text {th }}$ Edition. NY: Palgrave Macmillan.

Almeida, H.(2001). "Conceptions et Pratiques de la Médiation Sociale. Les modèles de médiation dans le quotidien professionnel des assistants sociaux", Coimbra: Fundação Bissaya-Barreto / Instituto Superior Bissaya-Barreto (439 pag.).

Autés, M. (2003). As metamorfoses do Trabalho Social. In Chopart, Jean-Noel (Org.). Os Novos Desafios do Trabalho Social. Dinâmicas de um campo profissional. Porto: Porto Editora, 255-278.

Autés, M (1981), Travail social et changement social-analyse d une action-recherche en milieu defavorise. Lille: CAF.

Beckett, C (2010). Assessment \& Intervention in Social Work. London: SAGE Publications Ltd

Bondu, D. (1998). Nouvelles pratiques de médiation sociale. Jeunes en difficultés et travailleurs sociaux. Paris: ESF.

Brites, C. e Barroco, M. L. (2001), "A Centralidade da Ética na Formação Profissional", in Henriquez, A (Org.), Netto, J, Maria L, Cabral, J, Jacques, C e Brittes, C. (2001). Serviço Social, Ética, Deontologia E Projecto Profissional. Lisboa, Madrid e S. Paulo: CPIHTS, Veras Editora e ICSA, p. 73-88

Brun, C. and Rapp, R. (2001). Strenghts-based Case Management: Individuals Perspetives on Strengths and the Case Management Relationship. Social Work, Vol. 46, n 3, 278-288.

Cardim, M; Mota, L e Pereira, L (2011). Será tudo da crise, ou devemos repensar o estado social?: A emergência de novos paradigmas. Sociologia on line, $n^{\circ} 2$, abril 2011, 517-550. (http://revista.aps.pt/cms/files/artigos_pdf/ART4dc419a91e849.pdf) [Consultado em 06/05/2012]

CMSA (2010). Standards of Practice for Case Management. Arkansas: Case Management Society of America, 30 pages. (www.csma.org) [consultado em 26-02-2012]

Compton, B. e Galaway, B. (Ed.) (1999). Social Work Processes. $6^{\text {th }}$ edition, N. York: Brooks/ Cole Publishing Company (266-391)

Cobb, S. (1993). Empowerment in mediation: A narrative perspetive. Negotiation Journal, 9 (3). pp 245-259.

Cobb S. (1997). "Una perspetiva narrativa en mediación", in Folger, J. P. y Jones, T. S. (compiladores). Nuevas direciones en mediación. Investigación y perspetivas comunicacionales. Paidós Mediación, $n^{\circ} 7,1^{a}$ edición. Buenos Aires.

Coulshed, V.; Mullender, A; Jones, D \& Thompson, N (2006). Management in social work. $3^{\text {rd }}$. Edtion, N.York: Palgrave Macmillan. (19-130).

Dolog, P, Krotzsch, M, Schaffert, S and Vrandecic, Denny (2009). Social Web and Knowledge Management. Universitat Karlsruhe, Institute AIFB. This work is supported by the European Union under the IST projects ATIVE. (http://www.ative-project.eu) and KiWi (http:// www.kiwi-project.eu). [consultado em 26-04-2012]

Duhme, F. (2001). Du travail Social au travail ensemble. Le partenariat dans le champ des politiques sociales. Paris: Editions ASH, 109-140.

Fisher, R., Ury, W. y Patton, B. M. (1998). Obtenga el Sí: el arte de negociar sin ceder. Gestión 2000, 1998, 4 $4^{\mathrm{a}}$ edición, Barcelona.

Fisher, T. (1987). Towards a Model of Co-Working in Family Conciliation. The British Journal of Social Work. Lancaster. Reino Unido

Folberg, P. (2007). Mediación Transformativa: Preservación del potencial único de la mediación en situaciones de dispuestas. Revista de Mediación, $n^{\circ}$ 2. Especial modelo transformativo. Asociación Madrileña de Mediación. Madrid. 
Franklin J.; Solovitz, B, Mason, M., Clemons, J., and Miller, G. (1987). An Evaluation of Case Management. American Journal of Public Health (AJPH), vol. 77, No 6, 674-678.

Freynet, M. (1996)., "Les paradoxes de la fonction de reliance du travail social" in Bolle De Bal, M., Voyages ao coeur des sciences humaines, De la reliance, Paris, Éditions Éditions l'Harmattan, Tome 2: Reliance et pratique, pp. 189-208.

Freynet, M.(1996). Les médiations du travail social, Contre l,exclusion, (re)construire les liens, Lyon, Chronique Sociale.

Gray, M. \& Webb, S. (2009). Social Work Theories and Methods.London: Sage Publications, Ltd.

Gaulejac V. \& al (1989). L'Ingénierie Sociale, Alternatives Sociales, Paris, Syros/Alternatives.

Guadalupe, S. (2009). Intervenção em rede. Serviço Social, Sistémica e Redes de Suporte Social. Coimbra: Imprensa da Universidade de Coimbra

Hahn, A, Aaron, P. and Kingsley, C. (1989). Case Management with At-Risk Youth. Center for Human Resources for the New York Community Trust and the Exxon Education Fund. Available on-line: http://smhp. psych.ucla.edu/qf/case_mgmt_qt/Case_Management_with_Atrisk_Youth.pdf [consultado em 26-04-2012]

Henriquez, A (Org.), Netto, J, Maria L, Cabral, J, Jacques, C e Brittes, C. (2001). Serviço Social, Ética, Deontologia \& Projeto Profissional. Lisboa, Madrid e S. Paulo: CPIHTS, Veras Editora e ICSA.

Ion, J. et Tricart, J.P. (1998). Les travailleurs sociaux, Paris, Éditions La Découverte, collection Repères.

Jaudon, R. (1982). "La fonction de médiation de lassistant social", in Informations Sociales, 4, pp. $67-75$.

Kanter, J. (1989). Clinical Case Management: Definition, Principles, Components. Hospital and Community Psychiatry April 1989 Vol. 40 No. 4 (361-368)

Kickert, W. e Koppenjan, J. (1997), "Public Management and Network Management: An Overview" in Walter Kickert, Erik-Hans Klijn e Joop Koppenjan (eds.). Managing Complex Networks: Strategies for the Public Setor, London, Sage, pp. 35-61

Lymbery, M and Postle, K.(Ed.) (2007). Social Work. A Companion to Learning. London: Sage Publications.

Martin, G. (1998). La dynamique des politiques sociales. Observation, Management, évaluation. Paris: Editions L'Harmattan.

Milburn, P. (2002). La médiation: espériences et compétences. Col. Alternatives Sociales, Paris: La Découverte Ed., 51-76; 127-166.

Ministério da Educação e da Ciência, Conselho Nacional de Educação (2011). Educação para o Risco, Recomendação 5/2011, DR, $2^{\text {oa }}$ série, 202, 20 de outubro.

Morse, G. et al. (1997). An Experimental Comparison of Three Types of Case Management for Homeless Mentally ill Persons. PSYCHIATRIC SERVICES. April 1997 Vol. 48 No. 4, 497-503.

NASW (1992). Standards for Social Work Case Management. Prepared by the Case Management Standards Work Group. Approved by the NASW Board of Directors, June 1992.

NASW (2012). Standards for Social Work Case Management. Prepared by the National Association of Social Workers, and Social Work Case Management Standards Experts Panel. Draft, April 25 (47 pages).

Netto, J.P. (2001). "A construção do projecto Ético-político do Serviço Social frente à Crise Contemporânea" in Henriquez, A (Org.), Netto, J, Maria L, Cabral, J, Jacques, C e Brittes, C. (2001). Serviço Social, Ética, Deontologia E Projecto Profissional. Lisboa, Madrid e S. Paulo: CPIHTS, Veras Editora e ICSA, p. 11-29 
Noguès H. (1998). "L'analyse des besoins sociaux" in Martin, G. (éd.), La dynamique des politiques sociales, Observation, management, évaluation, Paris, Éditions l'Harmattan, pp. 163-188

Olivera, M. G. (2005). Mediación Comunitária. Bases para implementar un Centro Municipal de Mediación Comunitária y de Resolución de Conflictos.Buenos Aires: Espacio Editorial.

Osh (2008). Social Worker / Case Management Performance Sandards. City of Philadelphia Health and Opportunities, Pensilvania: Office of Supportive Housing Revised 2008 (44 pages).

Payne, M. (2000). The politics of case management and social work. International Journal of Social Welfare, 2000, $\mathrm{n}^{\circ}$ 9, 82-91. Blackwell Publishers.

Payne, M. (2002). Teoria do Trabalho Social Moderno. Coimbra: Quarteto

Petitclerc, J.M. (2002). Pratiquer la médiation Sociale. Un nouveau métier de la ville au service du lien social. Paris: Dunod, 53-66, 132-145.

Ramsbothan, O., Woodhouse, T. y Miall, H. (2011). Resolución de conflitos. La prevención, gestión y transformación de conflitos letales. Barcelona: Edicions Bellaterra, S.L.

Robertis, C. (1981). Methodologie de lintervention en travail social. Paris: Centurion Ed.

Rodriguez, D.; Barbuzano, E. (2011). Qué puede aportar la mediación intercultural al ámbito sanitario? ENE. Revista de Enfermería. 5(3): 59-65 http://www.enfermeros.org [consultado em 26-04-2012].

Sanicola L. (dir.) (1994), L'intervention de réseaux, Paris, Bayard Éditions, collection Travail Social.

Sschõn D. (1987). The Refective Practitioner: How Professionals Think in Action, New York, Basic Books.

Schwartz, W. (1976). "Le modèle de médiation" in Shulman, L., Une technique de travail avec des groupes: le modèle de médiation, Paris, Éditions ESF, collection Pratiques Sociales, pp. 35-67.

Schwartz, W. (1984). "Entre o cliente e o sistema: a função mediadora" in Robert R.W. \& Northern, H., Teorias de Serviço Social de Grupo, Rio de Janeiro, Agir Editora, pp. 183-213

SCIE (2011). "We are more than our story": service user care and carer participation in social work education. London: Social Care Institute for Excellence. (www.scie.org.uk) [consultado em 26-03-2012].

Smale, G. (1996). Mapping Change and Innovation, London: NISW.

Sposati, A. \& al. (1985). A Assistência na trajetória das políticas sociais brasileiras uma questão em análise, S.Paulo, Cortez Editora, 1985.

Thompson, N. (2000). Understanding Social Work. Preparing for Practice. New York: Palgrave.

Thompson, N. (2007). Power and Empowerment. UK: Russel House Publishing.

Torremorell, M. (2008). Cultura de Mediação e Mudança Social. Col. Ciências da Educação Século XXI, 24, Porto: Porto Editora.

Unwin, P. and Hogg, R. (2012). Effective Social Work with Children and families. A skills Handbook. London: Sage Publications, Ltd.

White, V. and Harris, J. (2007). Management. In Lymbery, M. and Postle, K. (Ed.) Social Work. A Companion to Learning. London: sage Publications, (240-249). 
SÉRIE ENSINO

IMPRENSA DA UNIVERSIDADE DE COIMBRA

COIMBRA UNIVERSITY PRESS

2013

$\mathbf{U}$

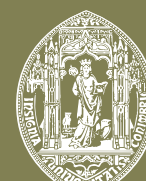

$\frac{\mathrm{I}}{\mathrm{U}}$

C • 